\title{
IL-13, Asthma and Glycosylation in Airway Epithelial Repair
}

\author{
Samuel J. Wadsworth, S. Jasemine Yang and Delbert R. Dorscheid
}

Additional information is available at the end of the chapter

http://dx.doi.org/10.5772/51970

\section{Introduction}

\subsection{Clinical assessment of asthma}

Pulmonary function tests (PFTs/spirometry) are routinely used clinically to diagnose asthma. Forced expiratory volume in one second $\left(\mathrm{FEV}_{1}\right)$ is a measure of airflow and is influenced largely by the resistance in the airways. During an "asthma attack", the airways narrow owing to mucus hypersecretion and smooth muscle contraction, which results in a sharp increase in airway resistance and reduction in FEV 1 . In the clinics, this can be reproduced by exposing patients with asthma to non-specific smooth muscle contractile agonists such as methacholine. A fall in $\mathrm{FEV}_{1}$ at a relatively low dose of methacholine indicates airway hyperresponsiveness (AHR). In asthmatic patients this drop in $\mathrm{FEV}_{1}$ can be reversed by inhaled bronchodilators such as $\beta 2$-agonists (e.g. salbutamol), which relaxes airway smooth muscles. AHR is often used as a diagnostic criterion for asthma.

Asthma is increasingly considered a syndrome, with diverse overlapping pathologies and phenotypes contributing to significant heterogeneity in clinical manifestation, disease progression, and treatment response [1]. Severe uncontrolled asthmatics make up approximately $5-10 \%$ of the population of asthmatics, yet they consume around $50 \%$ of the treatment resources [2]. Spirometric tests are incapable of exposing the underlying pathologies or phenotypes which combine within an individual to produce the asthmatic disease. In contrast specific biomarkers may enable more accurate sub-phenotyping of disease by indicating the pathology within an individual, and assist clinicians to better tailor the type and/or dose of therapy. In this way biomarkers have the potential to guide more effective personalized treatment regimes in asthma. 


\subsection{The causes of asthma}

Several studies have used lung biopsies taken from non-asthmatic patients and those who died from fatal asthma to show the airways of asthmatics possess characteristic structural differences, shown in Figure 1. These include but are not limited to; increased eosinophil numbers in asthmatics, and areas of focal bronchial epithelial denudation [3]. The contents of the bronchial lumen can also be examined using the bronchoalveolar lavage (BAL) technique, in which warm saline is instilled into a segmental bronchus of a patient and removed. BAL fluid-based studies confirmed the previous research that inflammatory cell influx and epithelial damage occur in the airways of asthmatics [3] [4]. It is a point of some debate as to whether the epithelial damage is caused by inflammation, is a cause of inflammation, or whether epithelial damage and airway inflammation are concurrent but unrelated processes. We shall discuss the potential role of the epithelium and epithelial repair in asthma in more detail later.

\subsection{Inflammation in asthma}

The rationale for treating severe asthmatics with steroids is centred on the assumption that the disease is driven by uncontrolled airway inflammation. The classical paradigm of the acute inflammatory response in allergic asthma is briefly; inhaled allergenic antigens are captured by professional antigen-presenting dendritic cells, macrophages, or epithelial cells. Antigens presented by these cells are recognized by $\mathrm{T}$-cells which proliferate and differentiate. Primed Th2 cells bind to B cells and release cytokines including triggering maturation of antigen-specific B cell populations into plasma cells. Plasma B cells release antigen-specific IgE that binds to IgE-receptors on mast cells in the airways, causing release of histamine-containing granules. Extracellular histamine released from mast cells binds to membrane receptors on airway smooth muscle cells triggering a rise in intracellular calcium, muscle contraction and airway narrowing. Although this paradigm has gained acceptance as an important mechanism in asthma, there is significant variation in specific cell types involved between individuals. In the setting of chronic asthma, eosinophils are thought to play a major role in maintaining airway inflammation in the long-term. Neutrophils are occasionally the predominate inflammatory cell present in the airways of chronic asthmatics, suggesting multiple underlying pathologies of disease. Neutrophilic vs. eosinophilic asthma are clinically indistinguishable by pulmonary function testing, but such pathological variation may have important implications regarding treatment as patients with "neutrophilic asthma" tend to be relatively unresponsive to steroid treatment [5]. A rapid and definitive method for determining the nature of airways inflammation in a diagnosed asthmatic is therefore needed to guide the clinician's selection of therapy.

\subsection{IL-13 and asthma}

Interleukin-13 (IL-13) is a pleiotropic Th2 cytokine secreted from a variety of inflammatory cells and structural cells, including the airway epithelium. IL-13 is upregulated in the airways of patients with allergic asthma exposed to allergen; segmental allergen challenge of 
atopic asthmatics triggered an increase of IL-13 protein and transcript in bronchoalveolar lavage, and the source was identified as mononuclear inflammatory cells [6]. Experiments in small mammals and in vitro studies using human cells, have demonstrated IL-13 triggers many of the pathophysiological characteristics of asthma, independent of the $\operatorname{IgE}$ and eosinophil inflammatory mechanisms classically associated with allergic disease [7] [8]. Genetic studies in humans have demonstrated the gene loci for IL-13 and the IL-4 receptor portion of the IL-13R $\alpha 1$ receptor have a strong genetic association to asthma susceptibility and severity [9]. IL-13 can act directly on the airway epithelium in various ways; previous studies have demonstrated IL-13 exposure of cultured human airway epithelial cells triggers an matrix-metalloproteinase-7 (MMP-7)-dependent release of the pro-inflammatory chemokine, soluble Fas-ligand, potentially leading to local inflammation and epithelial damage via removal of the protective Fas-ligand-mediated epithelial immune barrier [10]. Mucous hypersecretion is a common observation in asthmatic airways; acute treatment of differentiated cultures of primary human airway epithelial cells with IL-13 induces a hypersecretory phenotype [11], which develops into an asthma-like mucous hyperplasia with a 5-10-fold increase in goblet cell density and MUC5AC (the predominant airway mucin) detection after 14 day treatment [12]. Murine studies confirm IL-13 is required and sufficient to directly induce epithelial mucous hyperplasia in vivo in the absence of intermediate inflammatory cells [13]. Mucins including MUC5AC are highly glycosylated proteins, it thus follows that increased mucous production will necessitate an increase in the activity of associated transferase enzymes. In the H292 airway epithelial cell line, IL-13 treatment has been shown to increase the activity of the M and L isoforms of core 2 beta1, 6 $\mathrm{N}$-acetylglucosaminyltransferase $(\mathrm{C} 2 \mathrm{GnT})$ via activation of a JAK/STAT signaling pathway [14]. Thus, IL-13 acts directly on the airway epithelium to trigger development of an asthmalike phenotype, at least in part by increasing protein glycosylation via upregulation of glucosyltransferase activity.

\subsection{Current treatments for asthma}

Asthma is rarely fatal but often leads to significant patient morbidity. For over thirty years the mainstay therapy for asthma has been inhaled $\beta 2$-agonists $(\beta \mathrm{A})$, which relax the airway smooth muscles, causing bronchodilation, and inhaled glucocorticosteroids (i.e. steroids), which ameliorate airway inflammation and reduce the risk of asthma exacerbations. Steroids are anti-inflammatory drugs but also have many unwanted side-effects, particularly at high doses, including; weight-gain due to changes in body metabolism, and a reduction in bone mineral density, potentially leading to brittle bones. Therefore the decision to treat a patient with steroids should not be taken lightly. Inhaled $\beta_{2}$-agonists (s) are the most effective bronchodilators available and their main mechanism of action is via the relaxation of airway smooth muscle [15]. $\beta$ As interact with G-protein-coupled cell surface $\beta_{2}$-adrenoceptors $\left(\beta_{2} \mathrm{AR}\right)$ on bronchial smooth muscle cells and activate adenyl cyclase, causing a rise in intracellular cAMP, this results in relaxation of the smooth muscle and bronchodilation. Long term $\beta$ A treatment can result in a loss of response which shows variation between individuals. Desensitisation due to chronic $\beta$ A treatment is caused by a 
down-regulation of receptor transcription, secondary to a reduced activity of the CREB (cyclic AMP response element binding protein) transcription factor [15]. The $\beta_{2-}$ adrenoceptor gene possesses at least three possible GRE binding sites for the activated GCR, and GCs have been shown to increase $\beta_{2} A R$ transcription two-fold in human lung preparations in vitro and also in rat lungs in vivo. The downregulation of $\beta_{2} A R$ transcription resulting from long-term $\beta$ A treatment can therefore be reversed by a GC, so there is no net change in the level of $\beta_{2}$ ARs expressed in the bronchial epithelium or airway smooth muscle of animals treated with a combination of GCs and $\beta$ As [15]. The very large $\beta_{2} A R$ reservoir in airway smooth muscle cells may mean that this upregulation by GCs is functionally unimportant in vivo [15]. Many asthmatics who are unresponsive to high doses of steroids show a marked improvement in symptoms when given steroids with $\beta \mathrm{A}$ together. Thus there may be a true synergy between the two classes of drugs as $\beta_{2}$-adrenoceptor agonists enhance the function of GCs both in vitro and in vivo, possibly by increasing the nuclear localisation of activated GCRs. Low-dose theophylline has been prescribed as an asthma treatment for many years, however it has now been relegated to a third-line therapy according to the global asthma guidelines (reviewed in [16]). Theophylline is a weak, nonspecific cyclic nucleotide phosphodiesterase (PDE) inhibitor, and recently these PDE inhibitory characteristics have re-ignited interest in this drug as a possible asthma treatment.

Monoclonal antibodies have gained recent credence as a potential means to target therapy against specific receptors and signalling pathways. Omalizumab, a biologic agent that binds to IgE, has shown some promise as a means of controlling some difficult to treat asthma patients who are poorly controlled with standard inhaled steroid and $\beta$-agonist combination therapy (reviewed in [17]). Interleukin-5 (IL-5) is an important cytokine for eosinophil differentiation, maturation, migration into the circulation and survival. Various studies have implicated the eosinophil as being the primary cell responsible for airway hyperresponsiveness in asthma, thus anti-IL-5 antibodies have been developed (such as mepolizumab) with the intention of reducing airways hyperresponsiveness by preventing eosinophil recruitment and survival in the airway. Clinical trials have demonstrated such inhaled anti-IL-5 therapy does indeed reduce airway eosinophilia, but does not have a clinically-beneficial effect on lung function $[18,19]$. Considering the highly important role IL-13 is thought to play in asthma, it is unsurprising that therapies are being developed to specifically target IL-13. Lebrikizumab, an anti-IL-13 monoclonal antibody, has just completed phase II clinical trials in which patients with poorly-controlled asthma were given the drug subcutaneously at 4 weekly intervals for 6 months [20]. This study found anti-IL-13 therapy did significantly improve lung function, but only in a sub-group of asthma patients who exhibited high serum periostin levels, a surrogate marker of high airway IL-13 [20]. These studies demonstrate highly-targeted therapies may be useful in asthma, but each individual drug will probably only prove effective in a specific sub-group of asthmatic patients. The potential for such personalised medicine highlights the importance for accurate phenotyping of asthmatic individuals, discussed in the biomarkers section of this chapter (Section 5). 


\subsection{Carbohydrates and asthma}

Carbohydrate decoration of proteins has been associated with asthmatic disease. Two casecontrol studies have investigated the role of the histoblood group antigens; $\mathrm{H}(\mathrm{O}), \mathrm{A}, \mathrm{B}$, or $\mathrm{AB}$ in asthma susceptibility. They found in human subjects the O-secretor mucin glycan $(\mathrm{H}-$ antigen) phenotype is associated with an increased susceptibility to recurrent asthma exacerbations [21].

\section{Normal airway structure}

From the level of the bronchioles upwards, the stratified epithelium lining the airway lumen rests on a basal lamina or 'true' basement membrane, a specialised 'mat' of extracellular matrix proteins. Below the basal lamina is a layer of collagenous matrix, termed the reticular basement membrane, in which fibroblasts are embedded in a sporadic arrangement. Farther below the fibroblastic layer are arranged bundles of smooth muscle myocytes, blood vessels and afferent nerve endings.

\subsection{Structural changes to the airway in asthma}

Although asthma is considered an inflammatory disease, there are many structural changes in the airways. Figure 1. shows cross-sections through the large airways of two patients, one normal and one severe asthmatic. The Movat's pentachrome stain clearly highlights the various architectural remodeling events occurring in the asthmatic airway. Obstruction of the airways from excessive mucus production is a common finding in severe asthmatics, blue staining in the epithelium and the lumen demonstrates mucous cell hyperplasia, with excessive mucus deposition into the airway. Under the asthmatic epithelium a thicker basement membrane is present which contains several different extracellular matrix (ECM) factors (including tenascin-C) compared to normals [22]. Deeper into the airway, red-stained muscle mass is increased in the asthmatic owing to a combination of smooth muscle hypertrophy and hyperplasia (reviewed in [23]). The airways of severe asthmatics also demonstrate a fibrotic response with increased connective tissue deposition and fibroblast and myofibroblast proliferation. Opinion is divided as to whether inflammation precedes airway remodeling, or whether the two occur in parallel (reviewed in [15, 24, 25]). Evidence tends to favour the latter because; firstly, remodeling occurs very early on in the disease, and in some cases in the absence of inflammation [26], secondly, there is only a weak link between airway inflammation and symptoms [27], and thirdly, epidemiological data demonstrate steroids do not work in all asthmatics [5]. In reality it is likely effective therapies will need to target both airway inflammation and remodeling.

\subsection{Airway epithelial structure and function}

The bronchial epithelium lines the inner wall of the respiratory tract in a continuous layer; it forms the interface between inspired air and the internal milieu as well as being the primary target for inhaled respiratory drugs. In the larger airways and down the respiratory tree to 
the level of the bronchioles the epithelium is at least two cells thick (reviewed. in [28]). Although there are at least eight morphologically and functionally distinct epithelial cell types present in the respiratory tract, they can be classified into three main groups; basal, ciliated columnar, and secretory columnar (reviewed in [29]).

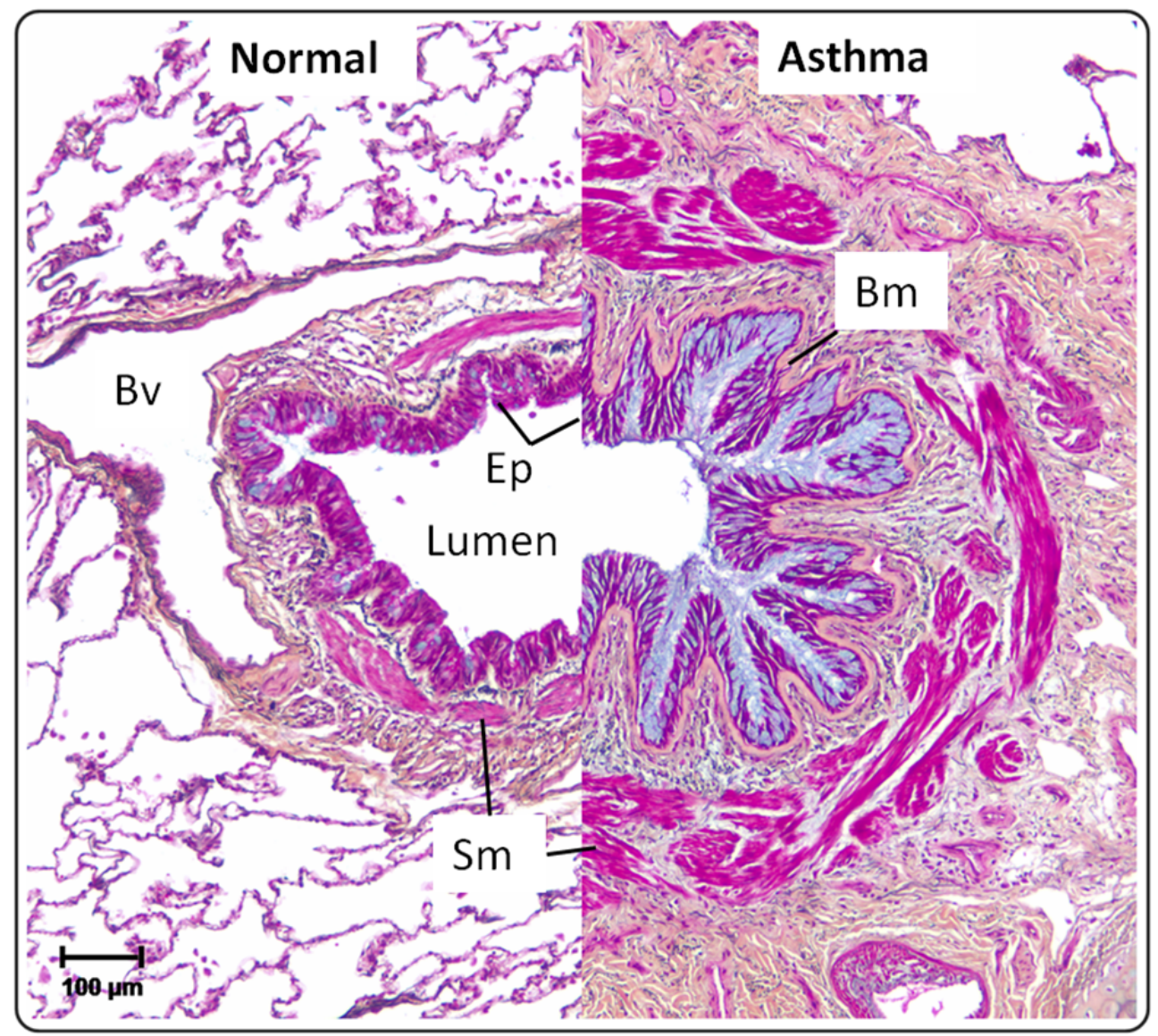

Figure 1. The airways in asthma undergo significant structural remodeling. Medium-sized airways from a normal and severe asthmatic patient were sectioned and stained using Movat's pentachrome stain. The epithelium (Ep) in asthma shows mucous hyperplasia and hyper secretion (blue), and significant basement membrane $(\mathrm{Bm})$ thickening. Smooth muscle $(\mathrm{Sm})$ volume is also increased in asthma. $\mathrm{Bv}=$ blood vessel. Scale bar $=100 \mu \mathrm{m}$.

\section{Basal cells}

Basal epithelial cells are pyramidal-shaped cells with a low cytoplasm to nucleus ratio, although found throughout the airway, their contribution to epithelial volume decreases with airway size (reviewed in [29]). Basal cells are anchored to the underlying basement membrane and to other cells via specialised adhesion structures discussed below (Figure 2.) 
$[4,30]$. Historically the basal cell has been considered to be the stem cell of the bronchial epithelium (reviewed in [31]), however animal studies suggest there may be alternative stem cells located in the airway epithelium, including secretory cells, and cells located at specialised niches including the broncho-alveolar junction and the neuroepithelial bodies.

\section{Columnar ciliated cells}

Columnar epithelial cells lie above the basal cell layer and line the airway lumen, in direct contact with the inspired air. Ciliated cells are terminally differentiated columnar cells and are the most common cell-type in the bronchial epithelium, accounting for around $50 \%$ of all epithelial cells and $80 \%$ of terminally-differentiated apical cells in the human trachea [32], reviewed in [29]. Their main function is the removal of particulate matter by means of the mucociliary pathway. Ciliated cells arise from either a basal or secretory cell pre-cursor and possess around 300 cilia per cell, directly beneath the cilia are observed numerous mitochondria and a dense microtubule system, reflecting the high metabolic demands of particle clearance [29] [33].

\section{Secretory cells}

Secretory cells are also present at the apical surface, comprising 15 to $20 \%$ of the normal tracheobronchial epithelium [32]. In the larger airways the mucus-secreting goblet cell represents the predominant secretory cell and is the main source of airway mucus. These cells are characterised by membrane-bound electron-lucent acidic-mucin granules which are released into the airway lumen to trap inhaled particles and pathogens, prior to removal from the respiratory tract by coordinated cilia beating. Serous cells and Clara cells are relatively rare secretory cells in the larger airways present in large airways, but Clara cells are the main secretory epithelial cell type of the bronchioles, particularly the most distal bronchioles (reviewed in [34]). Several studies in rodents indicate the progenitor cell of the bronchial epithelium is not the basal cell but it is in fact the non-ciliated, secretory columnar cell. Both goblet and clara cells have been observed to undergo de-differentiation and proliferation during in vivo wound repair [4] [35-38].

\subsection{Airway epithelial carbohydrate expression}

The airway epithelial surface is covered by a layer of airway surface liquid (ASL), mainly of epithelial origin. A layer of mucins form a mucous layer that overlies the thin watery periciliary layer (PCL). The predominant mucins in the airways are MUC5AC and MUC5B secreted by goblet cells and submucosal glands respectively. Mucins are highly glycosylated proteins; $70-80 \%$ of their molecular weight are carbohydrate, and the structural characteristics of the mucous layer depends on interaction between the carbohydrate sidechains of mucin proteins. Studies of airway mucins in disease, demonstrate mucins are both oversulphated and hyper-sialylated in patients with cystic fibrosis and in chronic bronchitis patients with significant infections [39]. Pseudomonas aeruginosa, the pathogen responsible for the majority of morbidity and mortality in cystic fibrosis patients, uses the sialylated and sulphated Lewis-x determinants as attachment sites. Thus mucin glycosylation patterns may 
significantly affect infection in the airway. Specific lectin-binding assays have been used to characterise carbohydrate expression patterns in differentiated human airway epithelium [40]. Out of 38 lectin probes tested, seven bound specifically to basal cells, seven to columnar cells, and three specifically labelled secretory cells. The 1HAEo- and 16HBE14o- airway epithelial cell lines were also probed with the same lectin panel, revealing identical carbohydrate expression to the basal epithelial cells in the human tissue [40]. Thus the different cell types in the pseudostratified epithelium of the airways, express specific patterns of carbohydrates, possibly reflecting their different functions.

\subsection{Airway epithelial functions}

The primary function of the bronchial epithelium is to serve as a continuous physical barrier and as such it functions as part of the non-specific immune system, preventing pollutants, bacteria, viruses, allergens, and other potentially noxious substances transferring from inspired air into the underlying mesenchyme. This defence is mediated by several adhesive mechanisms which have been elucidated through transmission electron microscopy and immunohistochemical studies of bronchial epithelial biopsies [4] [30] (Figure 2.). Belt-like tight junctions (zonula occludens) seal the lateral apices of columnar cells, regulating paracellular transport, whilst columnar cells adhere to each other via classical E-cadherin mediated adherens junctions [30]. Desmosomal cadherins mediate strong cell-cell adhesion and desmosomes are present between basal cells and particularly at the junction of basal and columnar cell layers [30]. Basal cells are in turn anchored to the basement membrane via specialised integrin-mediated cell-ECM junctions. Integrin heterodimers function by dynamically linking the contractile machinery of the cell's cytoskeletal network to the external matrix at specialised sites termed focal adhesions or focal contacts. The airway epithelium expresses several integrin heterodimers, including the $\alpha 6 \beta 4$ integrin which binds to laminin-5 in the basement membrane forming a hemidesmosome anchor with the ECM.

The bronchial epithelium is more than a passive barrier; it performs a variety of roles allowing it to function as a dynamic regulator of the innate immune system [39]. The mucociliary pathway represents the principle mechanism of particle clearance in the airway. Inhaled particles and pathogens (bacteria, viruses) are trapped in mucus prior to removal from the respiratory tract by coordinated cilia beating. In addition to producing mucus, secretory cells are the source of a variety of mediators capable of having direct effects on inhaled noxious agents; including anti-oxidants and a variety of anti-bacterial agents; lactoferrin, lysozyme, $\beta$-defensins and also opsonins, components of the complement system that coat bacteria to facilitate phagocytosis by macrophages (reviewed in [39]). Various immunoglobin isotypes are secreted onto mucosal surfaces where they act in a protective manner by opsonising bacteria and other pathogens, rendering them relatively harmless and activating phagocytosis and digestion by tissue macrophages. Allergen-specific IgA is secreted by activated B lymphocytes (plasma cells) in the sub-mucosa, dimeric $\operatorname{IgA}(\operatorname{dIgA})$ selectively binds to the polymeric Ig receptor (pIgR) expressed on the basal surface of basal airway epithelial cells. The pIgR-IgA complex is subsequently internalised and is transported to the apical surface via the endosomal pathway ready for secretion into the 
airway lumen. Dimeric secretory $\operatorname{IgA}(\operatorname{sIg} A)$ is released into the airway lumen as a $1: 1$ combination of $\mathrm{dIgA}$ and a portion of the pIgR known as secretory component (SC), which protects the IgA from digestion by proteases on the mucosal surface [40,41]. SC is a highly glycosylated protein containing 15\% N-linked carbohydrate. Glycosylated SC binds IL-8, inhibiting IL-8-mediated neutrophil chemotaxis and transendothelial migration. This interaction is dependent on SC glycosylation state as de-glycosylation with peptide $\mathrm{N}$ glycosidase F abolishes the SC-IL-8 complex [42].

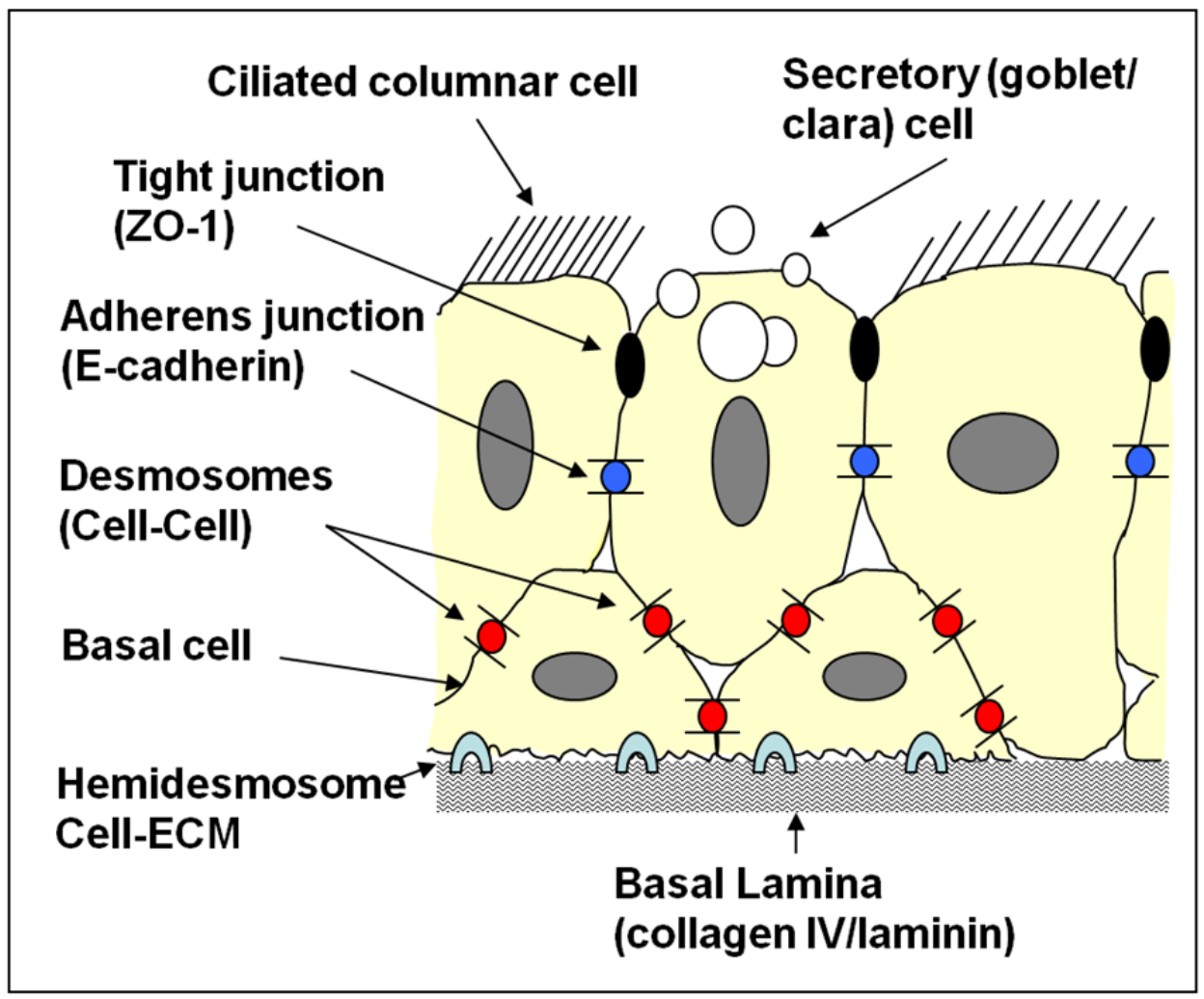

Figure 2. Adhesion mechanisms in the human bronchial epithelium. Tight junctions seal the lateral apices of columnar cells which adhere to each other via adherens junctions. Desmosomes mediate basalbasal and columnar-basal cell attachments, whilst hemidesmosomes anchor basal cells to the basal lamina. (Adapted from Roche et al. [30]).

\section{Epithelial injury and repair}

All epithelial tissues are regularly damaged as a consequence of exposure to environmental insults. Rapid repair following injury is crucial for restoring adequate barrier function, with subsequent cellular differentiation required to regenerate normal epithelial structure and function. The repair processes in all epithelial types have common elements producing an 
orderly progression of events including; cell spreading at the margins of the wound, cell migration into the wound, cell proliferation and finally re-differentiation (Figure 3). In vivo investigations of wound repair have demonstrated that migration and proliferation are both critical for the rapid restitution of the bronchial epithelium after injury [35-38]. Hamster tracheal epithelia were mechanically denuded to leave behind a bare (and sometimes damaged) basal lamina and wound repair was monitored until a morphologically normal epithelium was restored. Following epithelial removal, plasma promptly exudes into the injured site from the underlying vasculature to cover the denuded basement membrane, facilitating the binding of serum proteins to cellular receptors that stimulate repair of the damaged epithelium. At $12 \mathrm{~h}$ post-wounding, viable secretory and basal cells at the wound margins de-differentiate, flatten into a squamous morphology, and migrate at about $0.5 \mu \mathrm{m} / \mathrm{min}$ to cover the wound site.

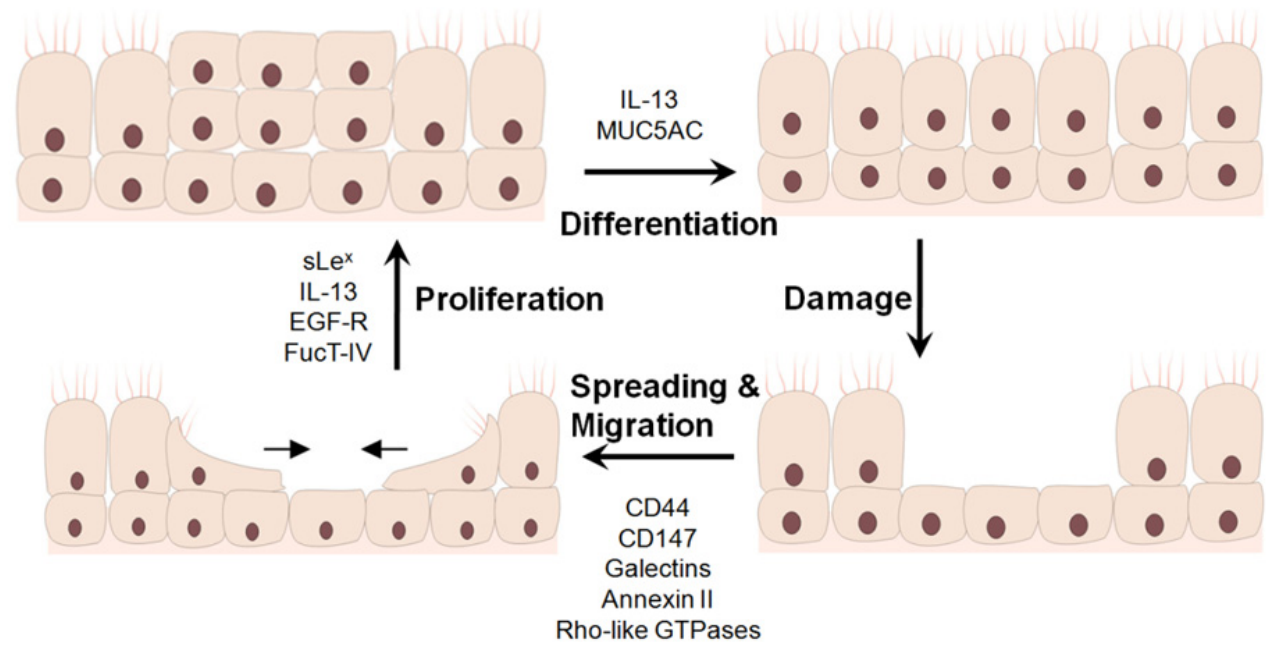

Figure 3. Airway epithelial repair involves a series of events including, cell spreading, migration, proliferation and differentiation. Following epithelial injury, neighboring cells flatten, spread and migrate to cover the site of injury. Subsequent proliferation and differentiation restores the epithelial structure and barrier function. The different stages of repair are mediated and facilitated by a diverse array of growth factors, cytokines and cell surface receptors, adhesion molecules, and intracellular enzymes, many of which are glycosylated. These glycans can modulate the function of proteins and lipids thereby regulating the repair process.

Proliferation is also an intrinsic component of epithelial repair. In the aforementioned hamster tracheal injury studies, mitosis rates at $12 \mathrm{~h}$ post-injury are low $(0.4 \%)$ but by $24 \mathrm{~h}$ a wave of proliferation occurs primarily in secretory cells, resulting in a multi-layered epidermoid metaplasia [35]. At 48h post-wounding proliferation rates decrease (although mitosis is still significantly above basal levels), from this time point onwards the upper-most cells of the metaplastic epidermis start to slough off, resulting in a gradual loss of the metaplastic phenotype, with subsequent regeneration of a functional mucociliated phenotype achieved by apical cell re-differentiation. In small wounds normal mucociliary 
structure is restored by $120 \mathrm{~h}$ but some persistent metaplasia persists in larger wounds through $168 \mathrm{~h}$ post-wounding [38]. Although both secretory and basal cells are involved in epithelial repair, secretory cells play a dominant role in these experiments, consistently demonstrating higher mitosis rates than any other epithelial cell type [35-38]. In vitro studies using muco-ciliated human bronchial epithelial cells grown in air-liquid interface (ALI) culture, demonstrate that scrape wound repair is achieved by rapid spreading and migration of cells at the wound edge, followed by proliferation of basal cells outside of the wound area [43]. Acute wound repair speeds were inhibited slightly by the steroid dexamethasone, but the same drug potentiated the ability of long-term ALI cultures to repair repeated wounds [43].

In vivo studies demonstrate epithelial repair is accompanied by a corresponding proliferation of the underlying mesenchyme. Hamster tracheal epithelial damage is followed at $24 \mathrm{~h}$ by capillary endothelial cell division, and at $36 \mathrm{~h}$ many fibroblasts were observed to be in mitosis [35-37]. Mesenchymal proliferation persisted for a longer period than the epithelial response and supports several in vitro studies demonstrating epithelial damage can influence the phenotype and proliferation of underlying fibroblasts [44, 45].

\subsection{Airway epithelial wound repair is compromised in asthmatics}

The patho-physiological changes observed in the asthmatic airway may be due to reactivation of the epithelial-mesenchymal trophic unit (EMTU), triggered by an abnormal epithelium that is held in a repair phenotype [24]. In vitro studies support the hypothesis that epithelial-derived factors are capable of altering the phenotype of adjacent mesenchymal cells $[43,44]$. The mechanisms involved in initiating and maintaining the epithelial repair response in asthma are largely unknown, however recent studies have demonstrated the airway epithelium in asthmatics is intrinsically altered compared to normals, and that these differences persist for extended periods in culture $[45,46]$. There is considerable evidence to suggest the airway epithelium is capable of orchestrating the inflammatory immune response, as following injury, epithelial cells release a variety of proinflammatory cytokines, chemokines and growth factors. Acute inflammation is a necessary aspect of wound repair, however if epithelial damage persists, or the epithelial repair response is not shut-off, then potentially deleterious chronic inflammation may result (Figure 4.).

\subsection{Mechanisms of cellular migration}

Many disorders characterized by impaired re-epithelialization, are not a result of inadequate proliferation, but are due to impaired cell migration over the denuded site [47-49]. Cell migration requires a coordinated, highly complex series of events including; changes to the cell cytoskeleton, modification of the surrounding ECM and modulation of adhesions to ECM substrate and to other cells. The majority of these processes are regulated by the Rholike family of small GTPases including, RhoA, B, C, E, Rac1, 2, 3 and Cdc42 (Figure 3.) (reviewed in $[50,51]$ ) that function by acting as "molecular switches", cycling between an 

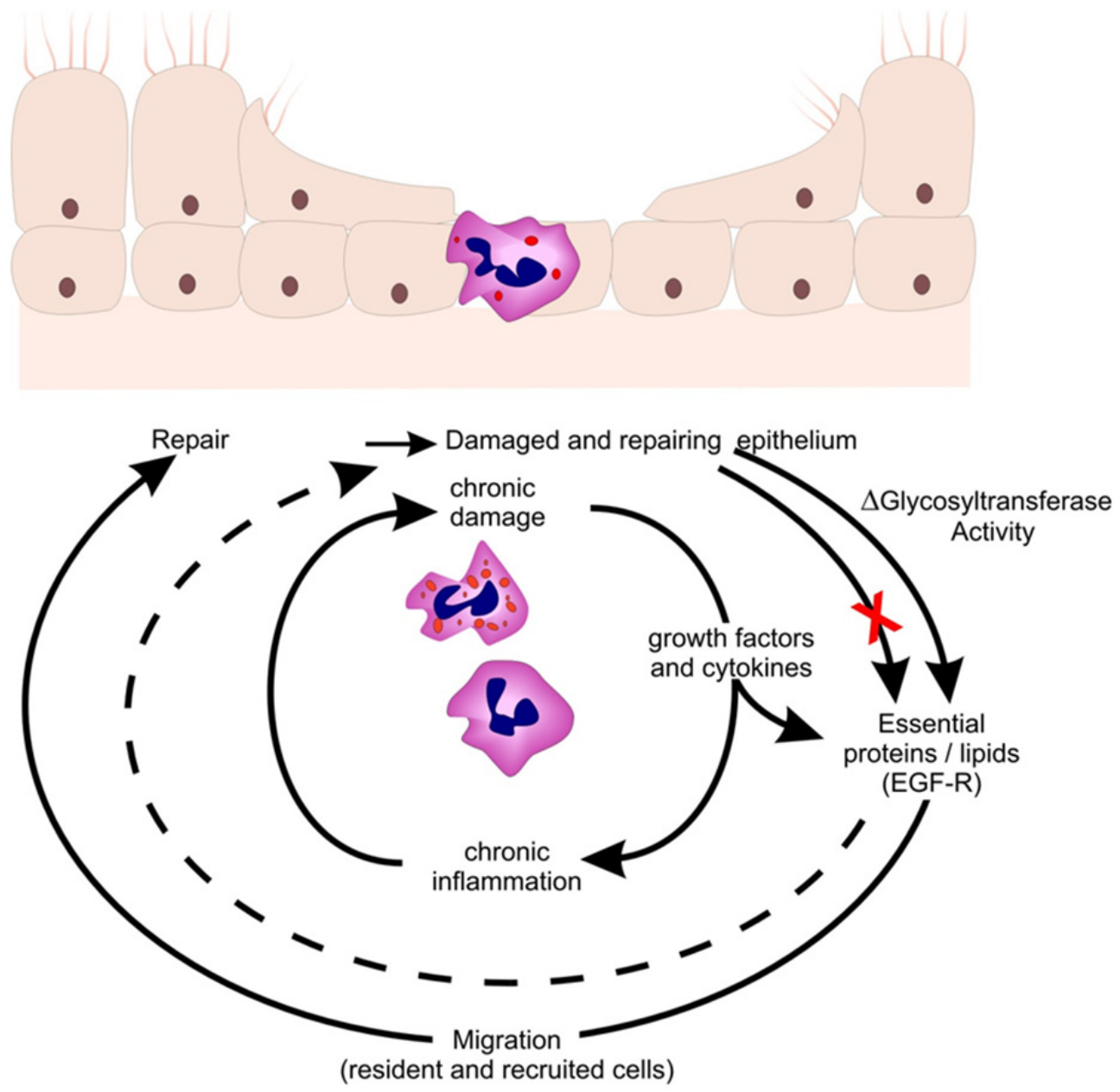

Figure 4. Injury and repair cycle of the airway epithelium in asthma. Complete repair requires glycosylation as a means of regulation of essential elements. Aberrant glycosylation would result in a defect in the mechanisms of repair, the accumulation of epithelial damage and persistent airway inflammation. Modified from Davies [46].

inactive GDP-bound state and an active GTP-bound form at the plasma membrane [52]. GTPases are able to regulate the transmission of signals from cell surface receptors, such as integrin-mediated cell-ECM adhesion, or growth factor ligation, to downstream intracellular signalling pathways, influencing the cell cytoskeleton, gene transcription, and the cell cycle (reviewed in [53]). Rho induces formation of stress fibres, integrin-mediated focal adhesions, and actomyosin-mediated cell body contraction [54], Rac-dependent actin polymerisation leads to lamellipodium extension and membrane ruffles at the leading edge of the cell [55], and Cdc42 induces formation of microspikes/filopodia [56]. 


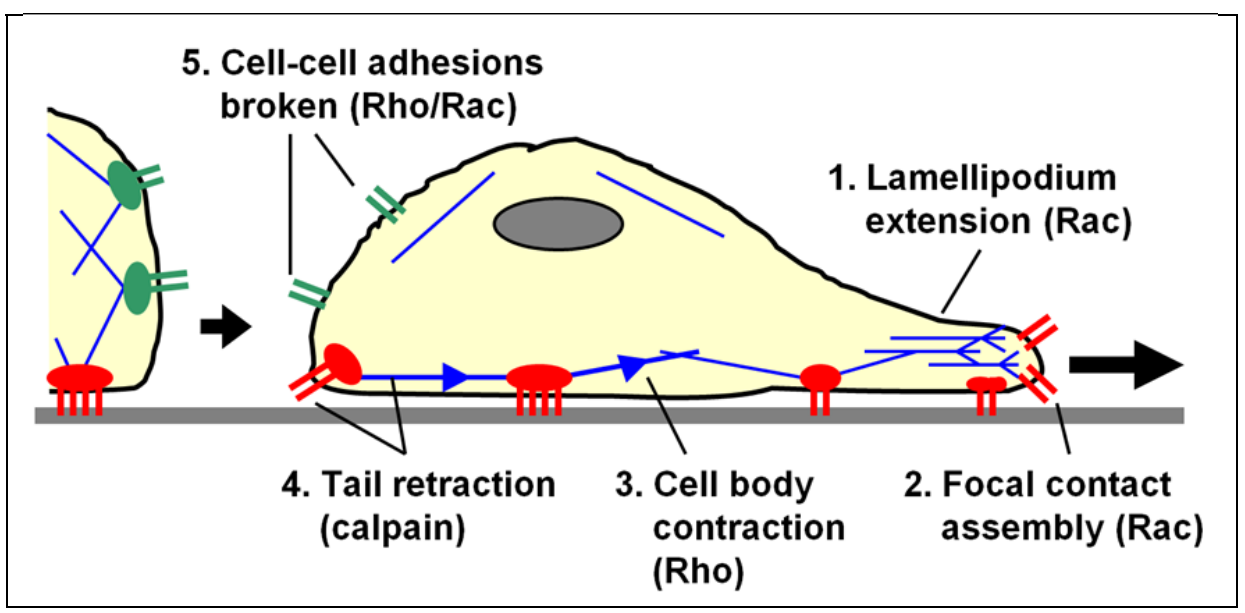

Figure 5. Cellular processes occurring during migration. The transition from a stationary state to a migratory phenotype involves several distinct mechanisms, Rho-like GTPases regulate the majority of these processes and the individual GTPases most directly linked to each are: (1.) Rac-dependent actin (blue) polymerisation leads to lamellipodium extension at the leading edge of the cell, (2.) new ECM adhesions are formed at the lamellipodium via focal contacts (red), also regulated by Rac, (3.) cell body contraction is dependent on actomyosin contraction (blue arrows) and is dependent on Rho activity, (4.) tail detachment is possibly affected by GTPase activity but the protease calpain is important for degradation of focal adhesions at the rear of migrating cells, (5.) cadherin-mediated cell-cell adhesions (green) are dependent on Rho and Rac activity and are often downregulated during migration. MMPmediated ECM degradation is necessary for migration, even in cells migrating over a basement membrane.

Several in vitro studies have demonstrated activity of the RhoGTPase family is essential for airway epithelial wound repair; activation of protein kinase A (PKA) facilitates scrape wound closure in cultured bovine airway epithelial cells via inhibition of Rho activity and decreased focal contact attachments [57]. The 16HBE human airway epithelial cell line has been used to demonstrate coordination of RhoA and Rac1 activities are vital for efficient wound closure [58]. Detachment of the trailing edge is often a limiting factor of cellular migration speed, detachment is possibly affected by GTPase activity but the protease calpain is important for degradation of focal adhesions at the rear of migrating cells. RhoGTPases are also involved in cell proliferation during airway epithelial repair; the scaffold IQ domain GTPase-activating protein (IQGAP1), an effector of Rho GTPases, is upregulated during 16HBE scrape wound repair and facilitates closure by increasing via a B-cateninmediated transcription of genes involved in cell cycle regulation such as CyclinD1 [59, 60].

\subsection{The effect of intracellular protein glycosylation on epithelial repair}

The activity of the Rho-GTPase family is highly regulated by glycosylation. Clostridium difficile toxins $\mathrm{A}$ and $\mathrm{B}(\mathrm{Tcd} \mathrm{A}$ and $\mathrm{TcdB}$ ) are major virulence factors for the induction of antibiotic-associated diarrhea and pseudomembranous colitis. These toxins possess potent 
cytotoxicity against cultured cell lines by inducing disaggregation of the cytoskeleton. TcdA and TcdB cellular toxicity is dependent on their intrinsic glucosyltransferase activity, they modify Rho-like GTPases by using UDP-glucose as a co-substrate [61]. RhoA undergoes mono-O-glucosylation at threonine-37, and Rac1 and Cdc42 are glucosylated at the homologous amino acid threonine-35. The threonine residue at position 37 of Rho (position 35 of Rac or Cdc42) is highly conserved and is located in the so-called effector region, it participates in co-ordination of the bound magnesium ion and thereby plays a pivotal role in nucleotide binding [62]. Glucose binding to residues within the effector region inhibits Rho-GTPase activity leading to drastic alteration of the cell cytoskeleton via several potential mechanisms including; inhibition of effector coupling, inhibition of nucleotide exchange (thereby directly blocking GTPase activity), by altering the sub-cellular localization of the GTPase, and finally by altering the stability of the enzyme within the cell (Reviewed in [52], [63]). TcdA has also been shown to induce apoptosis of intestinal epithelial cells via activation of caspases-3, -8 and -9 [64]. To date there is no direct experimental evidence linking Rho-GTPase glucosylation to the inhibition of wound repair in airway epithelial cells. However as this family of enzymes play such a fundamental role in repair of the airway epithelium, and the structure and function of the Rho-family of GTPases is very highly conserved, it is logical to presume that glycosylation would also play a pivotal role in regulating GTPase activity and thus wound repair.

\subsection{Role of cell surface glycoconjugates in epithelial repair}

Many proteins essential for normal cell physiology including adhesion molecules and cell surface receptors are glycosylated $[65,66]$. Alteration in the glycosylation pattern of many glycoproteins leads to changes in their function. It has been shown that impaired glycosylation of receptors often leads to abnormal intracellular trafficking, ligand binding and downstream signal transduction ability [67-70]. Tsuda et al. demonstrated that removal of sialic acid from erythropoietin leads to loss of its in vivo activity [71]. Complex carbohydrate structures attached to cell surface proteins and lipids have functional roles in cell motility [72], adhesion [73], proliferation [74], and growth potential [75] in several cell types. It also has been demonstrated that certain apical cell-surface carbohydrates are altered during cellular differentiation [76]. Thus many cellular functions are regulated and dependent upon glycoproteins. Because of the role of glycosylated structures in cell-cell and cell-matrix interaction, it is not surprising that there is a growing interest to explore the role for and regulation of these cell-surface carbohydrates in epithelial repair.

Lectins are naturally occurring proteins that can be isolated from a variety of plants and animals. Each lectin binds to a specific sugar moiety. As such, lectins are exquisitely selective tools to identify or block specific glycoconjugate motifs and have been extensively employed to study the role of cell-surface sugars and complex carbohydrates in cellular function [77, 78]. A variety of approaches have been employed to unravel the role(s) of carbohydrates in the multiple steps of the repair process. Some studies have investigated the expression pattern of different carbohydrates after injury using lectins as probes. Using three methods for localizing or quantifying lectin-binding sites Gipson et al. compared cell- 
surface of normal and migrating corneal epithelium of the rat. In their study they found that cell-surface of migrating epithelia express different sugar moieties relative to cell membranes of stratified stationary epithelia. There was a dramatic increase in concanavalin A (ConA) and wheat germ agglutinin (WGA) binding on migrating cells relative to stationary cells. The authors also showed that migrating cells have an increase in glycoprotein production determined by an increase in the incorporation of radiolabelled leucine and glucosamine. In addition they found that N-glycosylation of epithelial cells is necessary for epithelial cell migration $[79,80]$. Sweatt et al. demonstrated an increase in Nacetylgalactosamine in cell-surface glycoconjugates at the site of epithelial injury in pig cornea [81]. Dorscheid et al. has previously characterized cell-surface glycosylation in non-secretory cells of central human airway epithelium and airway epithelial cell lines utilizing lectinbinding patterns [82]. In this study it was shown that galactose- or galactosamine-specific lectins labeled basal epithelial cells and cell lines derived from basal cells. Lectins specific for several different carbohydrate structures bound columnar epithelial cells, and certain fucosespecific lectins labeled subsets of the airway epithelial cells. The cellular specificity of these differences suggests they may be relevant in various cellular functions. It has also been demonstrated that following mechanical injury of guinea pig tracheal epithelium, glycosylation profiles in the repairing epithelium change over time [83]. These changes may represent either the expression of one or more new glycoproteins, or changes in glycosylation of constitutive proteins, required for activation or a change in cell function needed for repair to proceed. Studies have shown that injury of the respiratory epithelium enhances $P$. aeruginosa adhesion and it has been speculated that changes of cell surface glycoconjugates related to wound repair, cell migration and/or spreading may favor P. aeruginosa adhesion [84].

In a previous study, Dorscheid et al. examined the functional role of cell surface carbohydrates in an in vitro model of wound repair after mechanical injury of human airway epithelial cells. The results demonstrated that N-glycosylated glycoproteins, particularly those with a terminal fucose residue, are essential in the adhesion and migration of airway epithelial cells and facilitate closure of epithelial wounds in monolayer culture [85]. Recently, Allahverdian et al. studied the role of a fucose containing tetrasaccharide, sialylLewis X (sLex) [NeuAc $\alpha 2-3 \mathrm{Gal} \beta 1-4(\mathrm{Fuc} \alpha 1-3)$ GlcNAc], in airway epithelial repair. Increased presentation of sLex was observed in areas of epithelial damage relative to areas of intact epithelium. In an in vitro model of bronchial epithelial repair, cell surface expression of sLex was shown to be significantly increased following mechanical injury of airway epithelial cell monolayers and inhibition of sLex completely prevented repair [86]. Further studies demonstrated that sLex decoration of epidermal growth factor receptor (EGFR) plays an important role in mediating airway epithelial wound repair [87]. Allahverdian et al. demonstrated that sLex co-localizes with EGFR and blocking of sLex with a neutralizing antibody resulted in reduced phosphorylation of EGFR and prevented repair. The final step in the synthesis of sLex is catalysed by a specific $\alpha-1,3$-fucosyltransferase, fucosyltransferase-IV (FucT-IV). Reduction in EGFR phosphorylation and repair were similarly observed when FucT-IV gene expression was knocked down using small interfering RNA (siRNA). These studies demonstrate the importance of cell surface carbohydrates in mediating airway epithelial repair. 
It has been shown previously by Donaldson et al. that the plant lectin concanavalin A (ConA), which binds glucose and mannose moieties, can inhibit migration of newt epidermal cells [88]. Gipson et al. cultured rat corneas with $3 \mathrm{~mm}$ central epithelial abrasions in the presence of four plant lectins. In this study the authors demonstrated that blocking glucose, mannose, and glucosamine sites on corneal epithelial cell surfaces and/ or the epithelial basement membrane reversibly slows or inhibits epithelial migration [78]. Using the same culture model of bronchial epithelial repair, Patchell et al. has demonstrated that following mechanical wounding of intact monolayers, the lectins Allomyrina dichotoma (AlloA) and chick pea agglutinin (CPA) differentially stain human airway epithelial cells in damaged areas relative to the staining of intact epithelial monolayers [89]. While AlloA positive staining cells are those that appear to be migrating from areas distant to the wound and accumulating in the wound, CPA positive staining cells are restricted to the leading edge of the wound. Moreover, the addition of the above lectins following mechanical wounding inhibited the repair. These results suggest that AlloA and CPA bind specific carbohydrate structures involved in normal epithelial repair. Further work is being carried out to determine the identity of the relevant proteins associated with these carbohydrate ligands.

In a study by Trinkaus-Randall et al., the effect of specific carbohydrate moieties of the basal lamina on the attachment and spreading of rabbit corneal epithelial cells was studied. Corneal epithelial basal cells were plated onto freshly denuded basal lamina and three lectins WGA, ConA and RCA were used to block specific sugar moieties in the basal lamina. This study showed that lectin binding of glucose, mannose, and galactose moieties on the basal lamina significantly altered the extent of cellular spreading, while the binding of glucosamine inhibited attachment. This study demonstrated that alteration of specific sugar moieties on the native basal lamina dramatically affects the ability of basal cells of corneal epithelium to attach or spread [90]. Using an in vitro model of airway epithelial repair Adam et al. demonstrate that lectin WGA which binds to $\mathrm{N}$-acetyl glucosamine residues inhibits the repair of epithelial damage without altering cell viability, while other $\mathrm{N}$-acetyl glucosamine binding lectins do not affect the repair process [81].

These studies clearly demonstrate the critical role of carbohydrates in the process of epithelial repair. However, carbohydrates must either modify a protein or lipid to regulate its function or participate in binding to a specific receptor to effect the desired action. As such, the biological role of glycans can be broadly divided into two groups. One group depends on the structural and modulatory properties of glycans and the other relies on specific recognition of glycan structures (generally receptor proteins or lectins).

\subsection{Galectins, annexins and epithelial injury - repair}

Galectins and annexins are two of possibly many families of proteins with carbohydrate binding capabilities. Although their role in epithelial repair remains unclear, recent studies highlight their importance in these processes. Galectins are a specific family of lectins with an affinity for $\beta$-galactose-containing oligosaccharides that have no enzymatic activity. To 
date, as many as 14 galectins have been identified, and they have been found in nonmammalian species such as birds, amphibians, fish, worms, sponges and fungi. The binding affinities of galectins are often greater for the oligosaccharides than the monosaccharide galactose. The expression of galectins is conserved however; their expression is often tissue specific and developmentally regulated. Different cells express a unique complement of galectins. Of the 14 galectins, eight have been identified in the nucleus and cytoplasm and participate in specific cellular functions. Nine galectins have been found extracellularly. Their presentation on the cell surface remains a mystery since they lack a signal sequence for secretion via the classical secretory pathway for membrane proteins.

Studies have shown that galectin-1 and galectin-3 have the potential to mediate cell-matrix interactions [92-95]. Their ubiquitous expression makes it difficult to understand the mechanism of their involvement in this process. In corneal epithelial cells, galectin-3 and galectin-7 have been characterized as mediators of epithelial cell migration, an essential component of epithelial wound repair $[96,97]$. Galectin immunostaining in healing wounds is more intense relative to normal epithelium, primarily at the leading edge and at areas of cell-matrix interactions [97]. Furthermore, wound repair was impaired in gal- $3^{-/-}$mice in the wound model systems of either alkali burn wounds that leave the corneal stroma intact or laser ablation wounds that result in damage to the underlying basement membrane. This impaired repair was not seen in gal-1/- mice. The authors propose that this effect is mediated by the lectin domain binding complementary glycoconjugates in the ECM and cell surface molecules resulting in enhanced cell-cell and cell-matrix interactions [97]. Similar work has demonstrated that galectin-7 also plays a role in corneal epithelial repair [96]. Although obvious differences exist between tissues, galectins may play a similar role in other epithelial organs and epithelial repair such as the lung and intestinal tract.

Annexins are a family of proteins that bind acidic phospholipids in a calcium dependant manner. Similar to galectins, annexins are largely cytoplasmic, however; several annexins have been detected on the cell surface of a variety of cells. Like galectins, annexins also lack a signal sequence for the cell surface presentation [98]. Annexins are proteins that have been associated with many cellular functions however their role remains poorly understood. Recent work has suggested that annexins possess carbohydrate binding abilities. This was first observed with annexin A4 when it was shown that it binds a variety of glycans [99]. Recent studies have suggested that annexin II (AII) is also capable of binding carbohydrates however this work is still in preliminary stages. Previously, the binding of tissue-type plasminogen activator (t-PA) was shown to bind HepG2 cells, however, following enzymatic removal of $\alpha$-fucose residues on t-PA, this binding was dramatically decreased [100]. Subsequently, AII has been shown to be a cell surface receptor for t-PA [101]. The importance of $\alpha$-fucose on t-PA may be a result of the carbohydrate binding of AII. Patchell et al. has shown that AII is presented on the cell surface and acts as a mediator of epithelial repair. AII was shown to be actively involved in wound repair in cells at the leading edge of the wound. Interestingly, the initial isolation purification of AII was achieved using a lectin, chick pea agglutinin, suggesting that itself, or an associated protein is glycosylated. Their tight association with the membrane and potential carbohydrate binding may influence the 
several functions associated with these relatively poorly understood proteins. On the surface of cells, AII has previously been shown to be involved in the migration of prostate cancer and lung carcinoma cells [102, 103]. In the case of metastatic cells, the regulation of cell migration and cell death is lost, however, under the appropriate levels of control, similar mechanisms of migration may be involved in the normal processes of wound repair. Following mechanical injury to rat cornea, at the leading edge of the wound AII translocates to the cell surface and interacts with the matrix protein tenascin-C [104]. The interaction of AII with tenascin- $C$ results in the loss of focal adhesions and cell migration in endothelial cells and has been shown to initiate downstream signaling pathways. These findings combined with previous results suggest that AII is involved in cell migration and repair. However, the mechanism of AII involvement in these cellular events is unknown but likely involves a fucose binding lectin activity to coordinate the needed response.

As a cell surface molecule, it has been suggested that AII is the human cytomegalovirus receptor [105]. Following the initial interaction with heparan sulfate proteoglycan, the virus particle is primed for membrane fusion and infection [106, 107]. As a membrane fusion protein, AII could potentially act as a receptor to other enveloped viruses such as respiratory syncytial virus (RSV). Recently, AII has been shown to bind RSV and was characterized as a potential cell surface protein that can promote RSV infection [108]. These findings along with data that has identified AII on the surface of airway epithelial cells provide strong evidence AII may be a cell fusion receptor allowing RSV infection of the respiratory tract. Viruses are a common source of lung injury, specifically the epithelium. Epithelial cells, as a protective mechanism, become highly apoptotic following virus infection to prevent further infection and viral persistence [109]. Viral infectivity of several enveloped viruses is dependent upon carbohydrate interactions between the viral proteins and their receptors. The end result is injury to the epithelium that requires repair. Altered glycosylation then may either increase the resulting injury from RSV infection or impair the AII coordinated repair.

\subsection{MMPs in asthma, glycosylation and repair}

Matrix-metalloproteinases (MMPs) are a family of zinc-dependant endopeptidases that digest all components of the extracellular matrix (ECM) and many non-ECM substrates including growth factors, cytokines, and their receptors [110, 111]. Several MMPs are increased in airway tissue and broncho-alveolar lavage (BAL) fluid of asthmatics including MMP-1, $-2,-3,-7,-8$ and $-9[112,113]$, suggesting a link between increased airway proteolytic activity and the asthma phenotype. In vivo studies have shown MMPs play a direct role in the development of allergic airway inflammation [114] and hyperresponsiveness [115-117]. Inflammatory cells, particularly neutrophils and alveolar macrophages, were thought to be the major source of increased proteinases in asthma and other inflammatory lung diseases $[118,119]$, however several groups have demonstrated structural cells of the lung including the epithelium, also synthesize MMPs and their endogenous tissue inhibitors (TIMPs) [10, 120-125]. MMPs perform many biological functions, they are integral to connective tissue homeostasis and their activities are strictly coordinated during epithelial wound repair [124- 
126]. Many growth factors such as TGF- $\beta$ and VEGF bind to sites in the ECM forming "reservoirs", and are released during ECM digestion [112]. Recent studies have provided strong evidence that dysregulated airway MMP activity in the lung epithelium may contribute to airway inflammation and the progression of tissue remodeling in asthma. MMP-7 expression is altered in the epithelium of asthmatics which may contribute to airway inflammation via cleavage and release of cytokines and chemokines including IL-25 and soluble FasL [10, 127]. It is possible that aberrant MMP expression in the airway epithelium contributes to inflammation and lung remodeling in asthma via proteolytic alterations in cytokine and chemokine signaling.

\subsection{IgCAMs in asthma, repair and the effects of IL-13}

Immunoglobulin-cell adhesion molecules (Ig-CAMs) are a diverse family of cell adhesion molecules characterised by the presence of one or more copies of a structure known as the Ig fold [128]. These receptors are expressed on a variety of cell types and are vital for many different biological processes, including neural development and immune system function [129]. In the adult, Ig-CAMs regulate the recruitment and subsequent activation of circulating lymphocytes, studies show they are also expressed in the epithelium and vasculature of the bronchial mucosa and levels of two Ig-CAMs, ICAM-1 and CD44 (hyaluronic acid receptor), are increased in the epithelium of asthmatics [130, 131]. Recent data also suggests a third Ig-CAM, CD147 (EMMPRIN - Extracellular matrix Metalloprotease Inducer) is increased in the epithelium of patients with chronic obstructive pulmonary disease (COPD) [132]. CD147 is over-expressed by metastatic cells of the skin, bladder, breast, and lung [92]. In cancer CD147 stimulates synthesis of various MMPs via homophilic interaction of CD147 oligomers on adjacent cells [134]. CD147 is potentially involved in various signaling pathways relevant to remodeling in airways disease, for an in depth review see [135]. Studies have shown CD147 is endogenously expressed at low levels in the basal cells of various stratified epithelia including the airway. Airway epithelial CD147 expression is increased in murine models of lung injury [136] and in several inflammatory airway diseases including pulmonary fibrosis [137] and interstitial pneumonias, where increased CD147 is associated with MMP-2, -7 (matrilysin) and -9 levels in the lungs of patients [138]. Recent studies have demonstrated CD147 is increased in the airway epithelium and BAL of patients with COPD, and signaling via CD147 regulates MMP-9 expression in cultured bronchial epithelial cells [132]. CD147 is potentially important in asthma; in a mouse model of allergic asthma, inhalation of a CD147neutralizing monoclonal antibody reduced ovalbumin (OVA)-induced airway mucin production and airway hyperreactivity, whilst partially inhibiting the recruitment of eosinophils and effector $\mathrm{CD}^{+} \mathrm{T}$ cells into lung tissue [139]. The authors attributed the reduced airways inflammation to an inhibition of the interaction between CD147 on inflammatory cells with cyclophilin chemokines. The reduction in OVA-induced mucous production suggests CD147 inhibition directly affects the epithelium.

MMP activity is dependent upon the close spatial juxtaposition of enzyme and substrate, therefore targeted MMP localization is a further mechanism of regulation. Specific MMP- 
substrate interactions can be facilitated and regulated at the cell surface via association of MMPs with chaperone molecules. CD44 is strongly upregulated in injured asthmatic airways and at the leading edge of repairing bronchial epithelial cells [43, 140], yet its function during airway epithelial repair is unknown. Studies suggest CD44 may co-ordinate MMP-substrate interactions at the plasma membrane by functioning as a docking molecule. In repairing reproductive epithelium, the v3 isoform of CD44 (CD44v3) forms a signaling complex with MMP-7 which is presented at the cell surface in close proximity to a potential substrate, pro-Heparin-Binding Epidermal-like Growth Factor (pro-HB-EGF). MMP-7 cleaves pro-HB-EGF into an active soluble form which triggers recruitment and activation of the Erb-B4 receptor (a member of the EGFR family) [141]. The EGF pathway is essential for efficient repair of the bronchial epithelium [43], and a similar mechanism of targeted MMP-7 presentation may occur during lung epithelial repair. Carbohydrate modification of proteins is essential for the creation of such micro-environments at the cell surface; in this case the interaction of MMP-7 (an non-glycosylated protease) with CD44 is dependent on the presence of branched glycosylated side-chains on the extracellular portion of the CD44 molecule. It is logical to extrapolate that a deficiency in the post-translational modification of CD44 could lead to a lack of MMP-7 binding, a reduction in HB-EGF activation, and a consequent inhibition of epithelial repair.

\subsection{How carbohydrates mediate cell-cell interaction and migration}

The glycans attached to matrix molecules such as collagens and proteoglycans are important for the maintenance of tissue structure, porosity, and integrity. Such molecules also contain binding sites for specific types of glycans, which in turn help with the overall organization of the matrix. Glycans are also involved in the proper folding of newly synthesized polypeptides in the endoplasmic recticulum and /or in the subsequent maintenance of protein solubility and conformation [66]. In this manner, altered glycosylation of matrix proteins may change adhesion properties and the potential of cell to migrate. This is due to either an altered conformation of the extracellular matrix of a change in the carbohydrate ligands available to bind.

Glycosylation of growth factor receptors has tremendous effects on the receptor function. Several studies have focused on the role of EGF and its family of receptors on epithelial repair [24, 142]. EGF, a well known mitogen for epithelial cells, has been used in to stimulate epithelial wound healing in guinea pigs as well as human airway cell monolayers and differentiated cells in vitro [43,143]. EGFR is known to be up-regulated upon the creation of a wound on airway epithelial monolayers in culture and correlated to the damaged areas of epithelium [24]. Increased tyrosine phosphorylation of the EGFR has also been observed after mechanical injury even in the absence of exogenous ligand [24]. While a critical role of signaling mediated by EGFR in repairing damaged epithelium has been well demonstrated in many epithelial systems, an important role for core glycosylation of extracellular domain of EGFR in ligand binding and tyrosine kinase activity has also been documented [105-107]. The extracellular domain of EGFR has 10 to 11 potential site for N-glycosylation. It has been shown that glycosylation is necessary for ligand binding and tyrosine kinase activity of 
EGFR [144-146]. Carbohydrate moieties of EGFR are critical for the direct interaction of the receptor with other structures [147]. Moreover, glycosylation defines localization of EGFR to specific domain of plasma membrane which could facilitate association of the receptor with other molecules and its transactivation [148]. Modification of receptor N-glycans can also regulate receptor trafficking and duration of cell surface residency [149]. A direct association between changes in glycosylation of EGFR and cellular events involved in epithelial repair such as migration and proliferation remains to be identified. It could be inferred that role of carbohydrates in epithelial repair is partly through their remarkable role in modulation of EGFR and other growth factor receptors.

The specificity of carbohydrate interactions allows for the high degree of selectivity found within the cell. Whether it is in regulating receptor activation, cell-cell or cell-matrix interactions or cell migration, defects in these processes may result in abnormalities and altered phenotypes. Their understanding will provide new avenues for research and therapies.

\section{IL-13 structure}

Interleukin-13 (IL-13) is a type I cytokine, comprised of four short $\alpha$-helical hydrophobic bundles joined by two disulfide bonds [111]. The cDNA of IL-13 has a single open reading frame that encodes 132 amino acids, including a 20-amino acid signal sequence that is cleaved from the mature secreted protein [112]. IL-13 has four predicted N-linked glycosylation sites and can either exist as a $17 \mathrm{kDa}$ glycoprotein or $10-12 \mathrm{kDa}$ unglycosylated protein [113]. IL-13 has been demonstrated to be secreted predominantly as the $10-12 \mathrm{kDa}$ unglycosylated protein [113]. In a study conducted by Liang et al., the distribution and expression levels of unglycosylated and glycosylated IL-13 was demonstrated to differ between human bronchial smooth muscle cells (BSMC) and lymphocytes [114]. Intracellularly, BSMC were shown to express higher levels of 12kDa unglycosylated IL-13, while lymphocytes expressed more of the $17 \mathrm{kDa}$ glycosylated form. However, lymphocytes secreted significantly higher levels of $12 \mathrm{kDa}$ unglycosylated IL-13 compared to BSMC. These findings suggest that cellular distribution of unglycosylated and glycosylated forms of IL-13 is tissue and cell type-dependent and may reflect the role of IL-13 in each cell type. The study also demonstrated that IL-13 secretion is regulated by human sulfatase modifying factor 2 (SUMF2), a protein predominantly found in the endoplasmic reticulum and highly expressed in BSMC [114]. SUMF2 was shown to physically interact with IL-13 and regulate its secretion irrespective of the glycosylation status of IL-13 in BSMC. Lymphocytes were shown to express lower levels of SUMF2 and to secrete higher levels of IL-13 compared to BSMC, further supporting the role of SUMF2 in regulating IL-13 secretion.

The glycosylation state of IL-13 can also affect its activity and potency to induce certain effector functions such as the up-regulation of low affinity IgE receptor, CD23 on the surface of monocytes. A functional study conducted by Vladich et al. [115] demonstrated that eukaryotic COS-7 cell-derived IL-13 was significantly more active in inducing the surface expression of CD23 on peripheral blood mononuclear cells (PBMC) compared to two 
different commercially available prokaryotic E. Coli-derived IL-13. The difference in bioactivity between the prokaryotic and eukaryotic-derived IL-13 molecules can be attributed to the fact that prokaryotic systems often lack post-translational modification steps such as glycosylation that take place in eukaryotic cells. These findings suggest the importance of glycosylation for IL-13 bio-activity.

\subsection{IL-13 function}

IL-13 is a pleiotropic cytokine that exerts its effect on a wide variety of cell types. IL-13 has a variety of functions which are critical to immune homeostasis and repair, but when uncontrolled contribute to the asthma phenotype. IL-13 is predominantly produced by T helper type 2 ( $\mathrm{Th}_{2}$ ) cells [116] and to a lesser extent by mast cells, basophils, and eosinophils $[117,118]$. IL-13 is also produced by a variety of non-hematopoietic cells including airway epithelial cells [119] and bronchial smooth muscle cells [114]. As a Th2 cytokine, IL-13 shares numerous overlapping characteristics with IL-4, where both cytokines promote B cell proliferation, IgE class switching and synthesis in B cells, and induce surface expression of antigens such as CD23 and major histocompatibility complex (MHC) class II [120]. These similarities between IL-13 and IL-4 function can be explained by the fact that the cytokines share a common receptor subunit, IL-4 receptor $\alpha$ subunit (IL-4R $\alpha$ ). However unlike IL-4, IL-13 does not exert direct effects on T cells and cannot elicit Th2 differentiation in naïve $\mathrm{T}$ cells; IL-13 is instead involved in mediating downstream Th2-effector functions [121]. In monocytes and macrophages, IL-13 can inhibit the production of various pro-inflammatory mediators such as prostaglandins, reactive oxygen species, IL-1, and TNF- $\alpha$ [113, 122]. IL-13 can also enhance the expression of several members of the integrin family that play important roles in adhesion, including CD11b, CD11c, CD18, and CD29 as well as induce surface expression of CD23 and MHC class II in monocytes and macrophages [121]. Furthermore, IL-13 has been reported to have direct effects on eosinophils, including promoting eosinophil survival, activation, and recruitment [123, 124].

IL-13 has important functions on non-hematopoietic cells, including endothelial cells, smooth muscle cells, fibroblasts, and epithelial cells. In endothelial cells IL-13 is a potent inducer of vascular cell adhesion molecule 1 (VCAM-1), which plays a role in eosinophil recruitment [125]. IL-13 has been shown to enhance proliferation and cholinergic-induced contractions of smooth muscle cells in vitro [126, 127]. In epithelial cells, IL-13 is a potent inducer of growth factors [128, 129] and chemokine expression [130]. It also induces epithelial cell proliferation [128], alters mucociliary differentiation [131], resulting in mucin production and goblet cell metaplasia $[7,132,133]$.

\subsection{IL-13R $\alpha 1$ structure and function}

IL-13 signals via a receptor system that consists of IL-13 receptor $\alpha 1$ (IL-13R $\alpha 1$ )/IL-4 receptor $\alpha$ subunit (IL-4R $\alpha$ ) and IL-13 receptor $\alpha 2$ (IL-13R $\alpha 2$ ). Both IL-13R $\alpha 1$ and IL-13R $\alpha 2$ belong to the type I cytokine receptor family, which possess several definitive features, including a WS-X-W-S motif, four conserved cysteine residues, fibronectin type II modules in the 
extracellular domain and proline-rich box regions in the intracellular domain [134]. The two receptors share $33 \%$ homology and $21 \%$ identity at the amino acid level [135] and their respective genes have both been mapped to the $X$ chromosome [136]. Kinetic analysis have revealed that IL-13R $\alpha 1$ and IL-13R $\alpha 2$ both bind specifically only to IL-13 and not IL-4, while IL-13 alone has no measurable affinity for IL-4R $\alpha$ [137].

IL-13R $\alpha 1$ is widely expressed on both hematopoietic and nonhematopoietic cells except human and mouse $\mathrm{T}$ cells and mouse B cells [112]. It is a $65-70 \mathrm{kDa}$ glycosylated transmembrane receptor protein with 10 predicted $\mathrm{N}$-glycosylation sites in the extracellular domain [138]. The cDNA for human IL-13R $\alpha 1$ encodes a 427 -amino acid sequence, including a 60-amino acid intracellular domain and 21-amino acid signal sequence [139]. A mutational analysis demonstrated that Leu319 and Tyr321 in the cytokine receptor homology module $(\mathrm{CRH})$ of human IL-13R $\alpha 1$ are critical residues for binding to IL-13 [135]. Interestingly, these residues are in close proximity to the predicted glycosylation sites of IL-13R $\alpha 1$, suggesting that the glycosylation state of IL-13R $\alpha 1$ could potentially influence receptor-ligand interactions.

IL-13R $\alpha 1$ binds IL-13 with low affinity by itself but binds IL-13 with high affinity when heterodimerized with IL-4R $\alpha$ to form a functional signalling receptor [138]. This signalling complex is known as the type II IL-4/IL-13 receptor and it also serves as an alternate receptor for IL-4. IL-13 is known to primarily signal through IL-13R $\alpha 1 / \mathrm{IL}-4 \mathrm{R} \alpha$ by first binding to IL-13R $\alpha 1$ chain with low affinity and then heterodimerizing with IL-4R $\alpha$ to become a stable, high affinity signalling complex [137]. The formation of IL-13R $\alpha 1 /$ IL-4R $\alpha$ results in the activation of the Jak kinases, Jak1 and Tyk2, followed by the recruitment of the transcription factor, signal transducer and activator of transcription 6 (STAT6) to the receptor. STAT6 is then phosphorylated and forms functional dimers that translocate to the nucleus to bind specific canonic DNA elements and initiate transcription of downstream genes [140]. Some examples of downstream targets of IL-13R $\alpha 1$ activation include eotaxin [141], MUC5AC [142], and, arginase I which is an enzyme important in the development of airway hyperreactivity [143].

\subsection{IL-13R $\alpha 2$ structure and function}

IL-13R $\alpha 2$ is a $56 \mathrm{kDa}$ glycoprotein that is expressed by a variety of cell types including monocytes, airway epithelial cells, fibroblasts, and keratinocytes [144, 145]. The cDNA of human IL-13R $\alpha 2$ encodes a 380-amino acid protein with a 26-amino acid signal sequence and a 17-amino acid intracellular domain [146]. IL-13R $\alpha 2$ contains four predicted glycosylation sites [147] and the glycosylation state of IL-13R $\alpha 2$ has been demonstrated to be important in its interactions with IL-13 [148]. IL-13R $\alpha 2$ exists in three cellular compartments: on the cell surface as a single trans-membrane receptor, in the cytosol within large intracellular pools, and in the extracellular space as a soluble form [149]. In fibroblasts and airway epithelial cells, IL-13R $\alpha 2$ has been demonstrated to be predominantly localized to intracellular pools that can be rapidly mobilized to the membrane upon stimulation by IL-13 and IL-4 [150]. 
IL-13R $\alpha 2$ has been considered for a long time as a decoy receptor which does not directly contribute to IL-13 signaling, but serves as a negative regulator to terminate IL-13 responses by directly binding to IL-13. The notion that this receptor had no signaling function arose from the fact that it has a short cytoplasmic tail that is missing two known signalling motifs [151] and does not bind JAKs or STATs [152]. IL-13R $\alpha 2$ has also been shown to be internalized quickly upon IL-13 binding [152]. Unlike IL-13R $\alpha 1$, IL-13R $\alpha 2$ alone has very high affinity for IL-13 [146] and this is further increased when IL-13R $\alpha 2$ exists as a soluble form [153]. N-linked glycosylation in the extracellular domain of IL-13R $\alpha 2$ has shown to be necessary for optimal IL-13 binding, demonstrating the importance of glycosylation in IL-13 signalling [148].

Recent investigations have suggested that IL-13R $\alpha 2$ acts as a signaling receptor not merely as a decoy receptor. Dienger et al. showed that IL-13R $\alpha 2$ knockout mice have attenuated rather than enhanced allergic airway responses, suggesting that under some circumstances, IL-13R $\alpha 2$ may contribute to IL-13 signaling [118] and reduce inflammation. Further evidence of anti-inflammatory properties comes from models of allergic asthma and chronic helminth infection where IL-10 and IL-13R $\alpha 2$ coordinately suppress Th2-mediated inflammation and pathology [154]. Fichtner-Feigl et al. has demonstrated that IL-13 signals through the IL$13 R \alpha 2$ to mediate TGF- $\beta$ production via the transcription factor, AP-1 in macrophages. [129]. These studies provide evidence that IL-13R $\alpha 2$ can serve as a functional signalling receptor but the role of glycosylation in regulating its signalling function has yet to be elucidated.

\subsection{IL-13 genetic and clinical linkage to asthma}

The gene encoding IL-13 consists of four exons and three introns and is located on chromosome 5q31 [155]. The chromosomal region 5q31 also contains genes for other molecules associated with asthma such as IL-4, IL-3, IL-9 and GM-CSF [156]. Previous studies have demonstrated strong associations between asthma and several single nucleotide polymorphisms (SNP) in the IL-13 gene, including +2043G $>$ A and $-1111 \mathrm{C}>\mathrm{T}$ [156, 157]. $+2043 \mathrm{G}>\mathrm{A}$ is within the IL-13 coding sequence and causes a positively charged arginine (R) to be substituted by a neutral glutamine (Q) at position 130, forming the IL-13 R130Q variant [158]. Position 130 is in the $\alpha$-D segment of the IL-13 molecule, where it has been demonstrated to interact with IL-13R $\alpha 1$ [159]. Compared to wildtype IL-13, the R130Q variant has previously been reported to have lower affinity for soluble IL-13R $\alpha 2$ due to slower association rates with the receptor [176]. IL-13R130Q is also more active compared to wildtype IL-13 in inducing STAT-6 activation and CD23 expression in monocytes [115]. The enhanced activity of IL-13R130Q may be explained by its decreased affinity to IL-13R $\alpha 2$.

\subsection{Roles of IL-13 in airway epithelial repair}

IL-13 has been demonstrated to be critical in mediating normal airway epithelial wound repair. In an in vitro model, Allahverdian et al. demonstrated that normal bronchial epithelial cells produce and secrete IL-13 in response to mechanical injury. IL-13 then mediates repair by inducing the production and autocrine/ paracrine release of HB-EGF, 
which subsequently activates EGFR and downstream signalling pathways required for repair [119]. In another in vitro study, thymic stromal lymphopoietin (TSLP) was shown to promote bronchial epithelial proliferation and repair via the upregulation of IL-13 production, providing further evidence for the critical role of IL-13 in repair [160]. IL-13 also plays a role in promoting normal airway epithelial health. Treatment of normal bronchial epithelial cells with IL-13 and IL-9 alone and in combination was shown to significantly reduce spontaneous cell apoptosis and to be protective against dexamethasone-induced cell apoptosis [161].

\section{The use of biomarkers in asthma diagnosis and therapeutic intervention}

Asthma is increasingly recognised as a heterogeneous syndrome with multiple patient phenotypes reflecting the varied underlying pathologies present in each individual. Pulmonary function testing has severe limitations; spirometry can identify a broad spectrum of asthmatics, but it is incapable of discerning sub-types of disease and therefore which individuals will respond to specific treatment regimes. Tissue biopsies and inflammatory cell counting in induced sputum, are accepted measures of determining airway inflammation, however both techniques are invasive, expensive and difficult to standardize, making them unsuitable for routine clinical use. Biomarkers hold the promise of being able to rapidly and specifically diagnose and monitor various sub-types of asthma in a noninvasive manner. The advantages and disadvantages of current and potential future biomarkers of airway inflammation for the diagnosis and monitoring of asthma in the clinic are reviewed in [162].

\section{1. "Invasive" airway biomarkers}

Tissue biopsies: To date the most accurate method to assess lung inflammation (and remodeling) is by histological examination of lung tissue. Sub-types of inflammatory cells can be identified in tissue sections using specific stains. Unfortunately the process of taking bronchial biopsies via bronchoscopy is invasive and requires experienced, skilled pathologists for tissue examination. In addition, clinical studies demonstrate a disconnect between the numbers of inflammatory cells counted in airway biopsies, and lung function in asthmatics [27].

Induced sputum: One alternative method of directly assessing airway inflammation is by sputum induction. A patient inhales nebulized hypertonic saline to trigger sputum production in the airways. The sputum is then coughed out along with any inflammatory cells present in the airway lumen. The main assumption is that the inflammatory infiltrate in the airway lumen reflects that in the tissue. Cytospins of the resulting sputum samples are then stained using similar techniques to tissue biopsies to examine the specific type of cellular infiltrate in the sputum. The principal output is the differential inflammatory cell count, expressed as a percentage, based on the manual counting of cells (eosinophils, neutrophils, lymphocytes, macrophages, and epithelial cells). The protein content of 
induced sputum may also have some value in diagnosing asthma. High mobility group box1 (HMGB-1), a ligand of the receptor for advanced glycation end products (RAGE), is a mediator in many inflammatory disorders. HMGB-1 is increased in the sputum of asthmatic patients, along with endogenous secretory RAGE, a soluble receptor that inhibits RAGE signalling [163]. Sputum induction is considerably less invasive than a tissue biopsy, but this technique is nonetheless uncomfortable for the patient. As many children are unwilling to undergo sputum collection in follow-up visits this technique tends to be limited to patients aged 8 years and above (although sputum induction has been performed successfully on younger children)[164]. Although the techniques of sputum induction and processing are well validated, they are time-consuming, require skilled people, and results are often difficult to reproduce and vary across centers.

\subsection{Exhaled biomarkers}

Less invasive means of obtaining airway biomarkers are desirable, particularly as diagnostic or disease monitoring tools in pediatric patients. The composition of exhaled breath is correlated to various disease states. This has been exploited by cancer researchers who have pioneered the use of gas sensor arrays, or "electronic noses", to aid the diagnosis of lung cancer [165]. As asthma is also a disease of the airways, it follows that the composition of exhaled breath will also be altered in the disease. The advent of so-called "breathomics" promises to revolutionize the way clinicians diagnose and treat asthmatics.

Fractional exhaled nitric oxide (FeNO): To date FeNO is the most widely used exhaled biomarker of airway inflammation in asthma. Levels of NO in exhaled breath can be measured relatively quickly in the clinic although the gas analyzers required are expensive [164]. FeNO is often increased in steroid naïve asthmatics and severe asthmatics, and is correlated with airway eosinophilia [166, 167]. FeNO is derived from the action of inducible NO synthase (iNOS) expressed by the airway epithelium [168] however the precise mechanism of how eosinophilia triggers iNOS activity in epithelial cells is undefined. It is unlikely that FeNO measurements per se would give any indication of the carbohydrate modifications of proteins in a patient, therefore this method will not be discussed further herein. For a more in-depth discussion of FeNO as a biomarker in asthma readers are referred to a recent review by Wadsworth et al. [162].

Exhaled Breath Condensate: The collection of exhaled breath condensate (EBC) and subsequent measure of inflammatory biomarkers is a relatively recent development. Exhaled breath condenses when it comes into contact with a cooled collector, allowing the collection of respiratory particles, droplets and water vapour. The $\mathrm{pH}$ of the EBC has been shown to relate to airway inflammation, low EBC pH indicates poorly controlled eosinophilic asthma in a similar manner to high FeNO [169]. It is unlikely that a single biomarker will be able to reflect the various pathologies which are present in a heterogeneous disease such as asthma. Therefore additional markers of airway inflammation will be needed to provide information complementary to that gained from FeNO or $\mathrm{pH}$ measurements. Many proteins are present in EBC and this method has been postulated as a means to allow the objective proteomic 
analysis of exhaled breath. As with $\mathrm{pH}$, several of these proteins are markers of oxidative stress including, cysteinyl leukotrienes, leukotriene B4, 8-isoprostane and hydrogen peroxide, although inflammatory proteins such as IL-6, IL-8, TNF- $\alpha$ may also be useful markers [170] (reviewed in [164]). Other proteins which do not obviously fit into any inflammatory pathway including; actin, cytokeratins, albumin, and hemoglobin have also been shown to be increased in the EBC of asthmatic patients [171].

\subsection{Non-exhaled biomarkers}

Serum proteins: As described above, biomarker studies in asthma have tended to concentrate on changes to the composition of exhaled breath. Although primarily a disease of the airways, there is mounting evidence to suggest there is also a systemic component to asthma [172]. If this is the case then circulating metabolites may be able to act as biomarkers of disease. Blood collection, serum isolation and analysis are highly standardized techniques of a minimally invasive nature and are therefore an ideal source of reproducible data. Serum proteins are already gaining credence as biomarkers in other inflammatory lung diseases. In COPD for example, not all smokers develop the disease, so being able to identify those who are at risk would be useful. Studies have shown circulating levels of pulmonary and activation-regulated chemokine (PARC)/CCL-18 are increased in COPD patients [173] and COPD patients who exhibit a rapid fall in $\mathrm{FEV}_{1}$ tend to have high circulating levels of fibrinogen [174]. Even accepted markers of cardiac dysfunction, cardiac troponin-T and Nterminal pro-brain natriuretic peptide (NT-proBNP) have been associated with increased mortality in patients with COPD, suggesting a cardiac component to the disease [175]. Several serum biomarkers have been demonstrated to be associated with asthma, including eosinophil cationic protein (ECP). ECP levels increase in response to allergen challenge, and decrease after allergen avoidance or inhaled corticosteroids (ICS) therapy, albeit in a less responsive manner than sputum eosinophils or FeNO (reviewed in [164]). In the clinic however, serum ECP levels do not reflect treatment-induced functional changes in chronic asthmatics, and serum ECP is unable to predict steroid responsiveness (reviewed in [164]). One randomized trial demonstrated that patients whose asthma management was based on serum ECP levels, experienced no improvement in symptoms compared to those treated using traditional monitoring techniques [176]. In addition, raised serum ECP levels may not be a specific marker of asthma; studies in pediatric patients have demonstrated serum ECP is also raised in cystic fibrosis and viral bronchiolitis [177]. Studies using purified ECP demonstrate it undergoes N-linked glycosylation and its cytotoxic activity against a cultured human small cell lung cancer cell line is dependent on both gene polymorphisms and glycosylation state [178]. Thus, rather than measuring total ECP, it is likely that analysing the proportion of total ECP which is glycosylated would prove to be a more specific biomarker for monitoring asthma progression. Other novel biomarkers are also altered in the circulation of patients with asthma. CCL-17 is a chemokine released from dendritic cells and epithelial cells after allergen contact, and is involved in the recruitment of Th2 cells into the lungs. Studies have shown sputum levels of CCL-17 is increased in the lungs of asthmatic adults,[179] whilst serum levels of CCL-17 is increased in children with asthma 
and is lowered in steroid-treated children with asthma [180]. In asthma, structural cells of the airway including the epithelium, release various pro-inflammatory chemokines such as IL-6 and IL-8 which trigger subsequent infiltration by immune cells. The epithelium also releases proteinases which are capable and necessary for the cleavage and activation of chemokinetic activity of molecules such as Fas-ligand and IL-25 [10] [127]. It is possible circulating levels of these chemokines and proteinases may provide an early warning for an imminent asthma exacerbation, or even indicate the particular sub-type of inflammation occurring in the patient.

Urinary metabolites: Data mentioned above suggests that the metabolism of patients with asthma is altered compared to normals. Urine is possibly the least invasive biofluid for biomarker measurements and is therefore highly suitable for the study and assessment of asthma in young children. Clinical studies have shown urinary biomarkers are potentially useful in asthma; levels of the downstream histamine metabolite, N-methylhistamine, is increased in the urine of patients with asthma, is increased after allergen challenge or exacerbation, and is reduced in asthmatic children taking anti-allergy medication [183, 184]. The human histamine receptor (hH1R) is a G-protein-coupled receptor, GPCRs are a large family of transmembrane receptors that are dependent on glycosylation for correct expression, trafficking and signaling. Studies using hH1R-expressing insect cells have shown that the receptor is N-glycosylated at a specific asparagene residue, Asn5 [185], whether glycosylation affects receptor activity, and how hH1R glycosylation could be measured in patients is unknown.

One recent study used nuclear magnetic resonance spectroscopy ( $\left.{ }^{1} \mathrm{H}-\mathrm{NMR}\right)$ to measure levels of 70 metabolites in the urine of children with and without asthma. NMR is an attractive method for urinary biomarker examination as it is able to provide qualitative and quantitative data on multiple compounds in a complex biofluid, without requiring significant pre-treatment of the sample. Urine was collected from control children without asthma (C), with stable asthma in the outpatient department (AO), and in children with unstable disease hospitalized for an asthma exacerbation (AED). NMR examination of urinary metabolites showed a $94 \%$ success rate in identifying AO children versus $\mathrm{C}$, and a similar success rate was seen when diagnosing AED versus AO asthma [186]. This study suggests the measurement of urinary metabolites is a potentially valuable technique to help clinicians diagnose and monitor asthma in children.

\section{Closing remarks}

In addition to forming a barrier against inhaled toxins, pathogens and allergens, the airway epithelium performs numerous innate immune and transport functions necessary for airway health and homeostasis. Damage to the epithelial layer is a common occurrence, thus complex repair mechanisms have evolved to rapidly restore the epithelial barrier, with subsequent regeneration of the fully functional differentiated tissue. In asthmatic airways, these epithelial repair mechanisms are compromised. 
The post-translational modification of proteins by glycosylation is capable of drastically affecting function via changes to; sub-cellular localisation and secretion, enzyme substrate binding, receptor-ligand binding, protein stability and degradation amongst others. Many of the proteins involved in the complex repair mechanisms defined in the airway epithelium are dependent on correct glycosylation in order to function correctly. There is accumulating evidence to suggest glycosylation is altered in airway diseases such as asthma. In addition, an important cytokine in asthma, IL-13, has a significant effect on the glycosylation state of the epithelial lining of the airway, and IL-13 signalling itself is affected by glycosylation of its receptors. Thus altered glycosylation of the airway epithelium, will have significant effects on the repair and regeneration of a functional airway epithelial barrier.

Asthma is a complex syndrome, individuals with asthma can be classified into a number of sub-phenotypes who will respond to different types of therapies. In order to facilitate the accurate diagnosis of asthmatics the development of specific bio-markers is required. Considerable research is being conducted into the use of non-invasive exhaled, urinary, or blood-borne markers of asthmatic disease to aid diagnosis in adults and children. To date the majority of biomarker research has concentrated on the identification of proteins linked to disease, rather than identifying differences in post-translational modifications. As glycosylation plays a fundamental role in regulating protein function, it is highly likely that future biomarkers for asthma will need focus on identifying alterations to the carbohydrate structures of proteins, particularly those involved in airway epithelial repair.

\section{Author details}

S. Jasemine Yang and Delbert R. Dorscheid and Samuel J. Wadsworth* James Hogg Research Centre, Institute for Heart + Lung Health, St. Paul's Hospital, University of British Columbia, Vancouver, Canada

\section{References}

[1] Wenzel, S.E., Asthma: defining of the persistent adult phenotypes. Lancet, 2006. 368(9537): p. 804-13.

[2] Adcock, I.M. and K. Ito, Steroid resistance in asthma: a major problem requiring novel solutions or a non-issue? Curr Opin Pharmacol, 2004. 4(3): p. 257-62.

[3] Djukanovic, R., et al., Quantitation of mast cells and eosinophils in the bronchial mucosa of symptomatic atopic asthmatics and healthy control subjects using immunohistochemistry. Am Rev Respir Dis, 1990. 142(4): p. 863-71.

[4] Montefort, S., et al., The site of disruption of the bronchial epithelium in asthmatic and nonasthmatic subjects. Thorax, 1992. 47(7): p. 499-503.

[5] Green, R.H., et al., Analysis of induced sputum in adults with asthma: identification of subgroup with isolated sputum neutrophilia and poor response to inhaled corticosteroids. Thorax, 2002. 57(10): p. 875-9.

\footnotetext{
${ }^{*}$ Correspong Author
} 
[6] Huang, S.K., et al., IL-13 expression at the sites of allergen challenge in patients with asthma. J Immunol, 1995. 155(5): p. 2688-94.

[7] Wills-Karp, M., et al., Interleukin-13: central mediator of allergic asthma. Science, 1998. 282(5397): p. 2258-61.

[8] Cohn, L., et al., Th2-induced airway mucus production is dependent on IL-4Ralpha, but not on eosinophils. J Immunol, 1999. 162(10): p. 6178-83.

[9] Beghe, B., et al., Polymorphisms in IL13 pathway genes in asthma and chronic obstructive pulmonary disease. Allergy, 2010. 65(4): p. 474-81.

[10] Wadsworth, S.J., et al., IL-13 and TH2 cytokine exposure triggers matrix metalloproteinase 7mediated Fas ligand cleavage from bronchial epithelial cells. J Allergy Clin Immunol, 2010. 126(2): p. 366-74, 374 e1-8.

[11] Danahay, H., et al., Interleukin-13 induces a hypersecretory ion transport phenotype in human bronchial epithelial cells. Am J Physiol Lung Cell Mol Physiol, 2002. 282(2): p. L226-36.

[12] Atherton, H.C., G. Jones, and H. Danahay, IL-13-induced changes in the goblet cell density of human bronchial epithelial cell cultures: MAP kinase and phosphatidylinositol 3-kinase regulation. Am J Physiol Lung Cell Mol Physiol, 2003. 285(3): p. L730-9.

[13] Whittaker, L., et al., Interleukin-13 mediates a fundamental pathway for airway epithelial mucus induced by CD4 T cells and interleukin-9. Am J Respir Cell Mol Biol, 2002. 27(5): p. 593-602.

[14] Beum, P.V., et al., Mucin biosynthesis: upregulation of core 2 beta 1,6 Nacetylglucosaminyltransferase by retinoic acid and Th2 cytokines in a human airway epithelial cell line. Am J Physiol Lung Cell Mol Physiol, 2005. 288(1): p. L116-24.

[15] Barnes, P.J., The role of inflammation and anti-inflammatory medication in asthma. Respir Med, 2002. 96 Suppl A: p. S9-15.

[16] Barnes, P.J., Update on asthma. Isr Med Assoc J, 2003. 5(1): p. 68-72.

[17] Kraft, M., Asthma phenotypes and interleukin-13--moving closer to personalized medicine. N Engl J Med, 2011. 365(12): p. 1141-4.

[18] Flood-Page, P., et al., A study to evaluate safety and efficacy of mepolizumab in patients with moderate persistent asthma. Am J Respir Crit Care Med, 2007. 176(11): p. 1062-71.

[19] O'Byrne, P.M., The demise of anti IL-5 for asthma, or not. Am J Respir Crit Care Med, 2007. 176(11): p. 1059-60.

[20] Corren, J., et al., Lebrikizumab treatment in adults with asthma. N Engl J Med, 2011. 365(12): p. 1088-98.

[21] Innes, A.L., et al., The $H$ antigen at epithelial surfaces is associated with susceptibility to asthma exacerbation. Am J Respir Crit Care Med, 2011. 183(2): p. 189-94.

[22] Laitinen, A., et al., Tenascin is increased in airway basement membrane of asthmatics and decreased by an inhaled steroid. Am J Respir Crit Care Med, 1997. 156(3 Pt 1): p. 951-8.

[23] Hirst, S.J., Airway smooth muscle as a target in asthma. Clin Exp Allergy, 2000. 30 Suppl 1: p. 54-9.

[24] Holgate, S.T., et al., Epithelial-mesenchymal interactions in the pathogenesis of asthma. J Allergy Clin Immunol, 2000. 105(2 Pt 1): p. 193-204.

[25] Hackett, T.L. and D.A. Knight, The role of epithelial injury and repair in the origins of asthma. Curr Opin Allergy Clin Immunol, 2007. 7(1): p. 63-8. 
[26] Malmstrom, K., et al., Lung function, airway remodelling and inflammation in symptomatic infants: outcome at 3 years. Thorax, 2011. 66(2): p. 157-62.

[27] Sont, J.K., et al., Relationship between the inflammatory infiltrate in bronchial biopsy specimens and clinical severity of asthma in patients treated with inhaled steroids. Thorax, 1996. 51(5): p. 496-502.

[28] Jeffery, P.K., Remodeling in asthma and chronic obstructive lung disease. Am J Respir Crit Care Med, 2001. 164(10 Pt 2): p. S28-38.

[29] Knight, D.A. and S.T. Holgate, The airway epithelium: structural and functional properties in health and disease. Respirology, 2003. 8(4): p. 432-46.

[30] Roche, W.R., et al., Cell adhesion molecules and the bronchial epithelium. Am Rev Respir Dis, 1993. 148(6 Pt 2): p. S79-82.

[31] Evans, M.J., et al., Cellular and molecular characteristics of basal cells in airway epithelium. Exp Lung Res, 2001. 27(5): p. 401-15.

[32] Rhodin, J.A., The ciliated cell. Ultrastructure and function of the human tracheal mucosa. Am Rev Respir Dis, 1966. 93(3): p. Suppl:1-15.

[33] Philippou, S., et al., The morphological substrate of autonomic regulation of the bronchial epithelium. Virchows Arch A Pathol Anat Histopathol, 1993. 423(6): p. 469-76.

[34] Nettesheim, P., J.S. Koo, and T. Gray, Regulation of differentiation of the tracheobronchial epithelium. J Aerosol Med, 2000. 13(3): p. 207-18.

[35] Keenan, K.P., J.W. Combs, and E.M. McDowell, Regeneration of hamster tracheal epithelium after mechanical injury. I. Focal lesions: quantitative morphologic study of cell proliferation. Virchows Arch B Cell Pathol Incl Mol Pathol, 1982. 41(3): p. 193-214.

[36] Keenan, K.P., J.W. Combs, and E.M. McDowell, Regeneration of hamster tracheal epithelium after mechanical injury. III. Large and small lesions: comparative stathmokinetic and single pulse and continuous thymidine labeling autoradiographic studies. Virchows Arch B Cell Pathol Incl Mol Pathol, 1982. 41(3): p. 231-52.

[37] Keenan, K.P., J.W. Combs, and E.M. McDowell, Regeneration of hamster tracheal epithelium after mechanical injury. II. Multifocal lesions: stathmokinetic and autoradiographic studies of cell proliferation. Virchows Arch B Cell Pathol Incl Mol Pathol, 1982. 41(3): p. 215-29.

[38] Keenan, K.P., T.S. Wilson, and E.M. McDowell, Regeneration of hamster tracheal epithelium after mechanical injury. IV. Histochemical, immunocytochemical and ultrastructural studies. Virchows Arch B Cell Pathol Incl Mol Pathol, 1983. 43(3): p. 213-40.

[39] Tam, A., et al., The airway epithelium: more than just a structural barrier. Ther Adv Respir Dis, 2011. 5(4): p. 255-73.

[40] Johansen, F.E. and C.S. Kaetzel, Regulation of the polymeric immunoglobulin receptor and IgA transport: new advances in environmental factors that stimulate $\operatorname{PIgR}$ expression and its role in mucosal immunity. Mucosal Immunol, 2011. 4(6): p. 598-602.

[41] Woof, J.M. and M.W. Russell, Structure and function relationships in $\operatorname{IgA}$. Mucosal Immunol, 2011. 4(6): p. 590-7.

[42] Martin, N. and I.D. Pavord, Bronchial thermoplasty for the treatment of asthma. Curr Allergy Asthma Rep, 2009. 9(1): p. 88-95. 
[43] Wadsworth, S.J., H.S. Nijmeh, and I.P. Hall, Glucocorticoids increase repair potential in a novel in vitro human airway epithelial wounding model. J Clin Immunol, 2006. 26(4): p. 37687.

[44] Zhang, S., et al., Growth factors secreted by bronchial epithelial cells control myofibroblast proliferation: an in vitro co-culture model of airway remodeling in asthma. Lab Invest, 1999. 79(4): p. 395-405.

[45] Morishima, Y., et al., Triggering the induction of myofibroblast and fibrogenesis by airway epithelial shedding. Am J Respir Cell Mol Biol, 2001. 24(1): p. 1-11.

[46] Davies, D.E., The bronchial epithelium: translating gene and environment interactions in asthma. Curr Opin Allergy Clin Immunol, 2001. 1(1): p. 67-71.

[47] Woodley, D., The Molecular and Cellular Biology of Wound Repair. 2nd ed, ed. R.A.F. Clark1996, New York: Plenum Publishing Corp. 339-354.

[48] Seiler, W.O., et al., Impaired migration of epidermal cells from decubitus ulcers in cell cultures. A cause of protracted wound healing? Am J Clin Pathol, 1989. 92(4): p. 430-4.

[49] Hanna, C., Proliferation and migration of epithelial cells during corneal wound repair in the rabbit and the rat. Am J Ophthalmol, 1966. 61(1): p. 55-63.

[50] Ridley, A.J., Rho family proteins: coordinating cell responses. Trends Cell Biol, 2001. 11(12): p. 471-7.

[51] Ridley, A.J., Rho GTPases and cell migration. J Cell Sci, 2001. 114(Pt 15): p. 2713-22.

[52] Schirmer, J. and K. Aktories, Large clostridial cytotoxins: cellular biology of Rho/Rasglucosylating toxins. Biochim Biophys Acta, 2004. 1673(1-2): p. 66-74.

[53] Sander, E.E. and J.G. Collard, Rho-like GTPases: their role in epithelial cell-cell adhesion and invasion. Eur J Cancer, 1999. 35(9): p. 1302-8.

[54] Ridley, A.J. and A. Hall, The small GTP-binding protein rho regulates the assembly of focal adhesions and actin stress fibers in response to growth factors. Cell, 1992. 70(3): p. 389-99.

[55] Ridley, A.J., et al., The small GTP-binding protein rac regulates growth factor-induced membrane ruffling. Cell, 1992. 70(3): p. 401-10.

[56] Kozma, R., et al., The Ras-related protein Cdc42Hs and bradykinin promote formation of peripheral actin microspikes and filopodia in Swiss 3 T3 fibroblasts. Mol Cell Biol, 1995. 15(4): p. 1942-52.

[57] Spurzem, J.R., et al., Activation of protein kinase A accelerates bovine bronchial epithelial cell migration. Am J Physiol Lung Cell Mol Physiol, 2002. 282(5): p. L1108-16.

[58] Desai, L.P., et al., RhoA and Rac1 are both required for efficient wound closure of airway epithelial cells. Am J Physiol Lung Cell Mol Physiol, 2004. 287(6): p. L1134-44.

[59] Wang, Y.P., et al., IQ domain GTPase-activating protein 1 mediates the process of injury and repair in bronchial epithelial cells. Sheng Li Xue Bao, 2008. 60(3): p. 409-18.

[60] Wang, Y., et al., IQGAP1 promotes cell proliferation and is involved in a phosphorylationdependent manner in wound closure of bronchial epithelial cells. Int J Mol Med, 2008. 22(1): p. 79-87.

[61] Just, I., et al., Glucosylation of Rho proteins by Clostridium difficile toxin B. Nature, 1995. 375(6531): p. 500-3.

[62] Herrmann, C., et al., Functional consequences of monoglucosylation of Ha-Ras at effector domain amino acid threonine 35. J Biol Chem, 1998. 273(26): p. 16134-9. 
[63] Sehr, P., et al., Glucosylation and ADP ribosylation of rho proteins: effects on nucleotide binding, GTPase activity, and effector coupling. Biochemistry, 1998. 37(15): p. 5296-304.

[64] Gerhard, R., et al., Glucosylation of Rho GTPases by Clostridium difficile toxin A triggers apoptosis in intestinal epithelial cells. J Med Microbiol, 2008. 57(Pt 6): p. 765-70.

[65] Zanetta, J.P., et al., Glycoproteins and lectins in cell adhesion and cell recognition processes. Histochem J, 1992. 24(11): p. 791-804.

[66] Lis, H. and N. Sharon, Protein glycosylation. Structural and functional aspects. Eur J Biochem, 1993. 218(1): p. 1-27.

[67] Hoe, M.H. and R.C. Hunt, Loss of one asparagine-linked oligosaccharide from human transferrin receptors results in specific cleavage and association with the endoplasmic reticulum. J Biol Chem, 1992. 267(7): p. 4916-23.

[68] Rands, E., et al., Mutational analysis of beta-adrenergic receptor glycosylation. J Biol Chem, 1990. 265(18): p. 10759-64.

[69] Feige, J.J. and A. Baird, Glycosylation of the basic fibroblast growth factor receptor. The contribution of carbohydrate to receptor function. J Biol Chem, 1988. 263(28): p. 14023-9.

[70] Leconte, I., et al., N-linked oligosaccharide chains of the insulin receptor beta subunit are essential for transmembrane signaling. J Biol Chem, 1992. 267(24): p. 17415-23.

[71] Tsuda, E., et al., The role of carbohydrate in recombinant human erythropoietin. Eur J Biochem, 1990. 188(2): p. 405-11.

[72] Schnaar, R.L., Glycosphingolipids in cell surface recognition. Glycobiology, 1991. 1(5): p. 477-85.

[73] Phillips, M.L., et al., ELAM-1 mediates cell adhesion by recognition of a carbohydrate ligand, sialyl-Lex. Science, 1990. 250(4984): p. 1130-2.

[74] Chammas, R., et al., Functional hypotheses for aberrant glycosylation in tumor cells. Braz J Med Biol Res, 1994. 27(2): p. 505-7.

[75] Lowe, J.B., et al., ELAM-1--dependent cell adhesion to vascular endothelium determined by a transfected human fucosyltransferase cDNA. Cell, 1990. 63(3): p. 475-84.

[76] Mann, P.L., I. Lopez-Colberg, and R.O. Kelley, Cell surface oligosaccharide modulation during differentiation. I. Modulation of lectin binding. Mech Ageing Dev, 1987. 38(3): p. 20717.

[77] Lis, H. and N. Sharon, The biochemistry of plant lectins (phytohemagglutinins). Annu Rev Biochem, 1973. 42(0): p. 541-74.

[78] Gipson, I.K. and R.A. Anderson, Effect of lectins on migration of the corneal epithelium. Invest Ophthalmol Vis Sci, 1980. 19(4): p. 341-9.

[79] Gipson, I.K. and T.C. Kiorpes, Epithelial sheet movement: protein and glycoprotein synthesis. Dev Biol, 1982. 92(1): p. 259-62.

[80] Gipson, I.K., et al., Lectin binding to cell surfaces: comparisons between normal and migrating corneal epithelium. Dev Biol, 1983. 96(2): p. 337-45.

[81] Sweatt, A.J., R.M. Degi, and R.M. Davis, Corneal wound-associated glycoconjugates analyzed by lectin histochemistry. Curr Eye Res, 1999. 19(3): p. 212-8.

[82] Dorscheid, D.R., et al., Characterization of cell surface lectin-binding patterns of human airway epithelium. Histochem J, 1999. 31(3): p. 145-51. 
[83] Xiantang, L., et al., Glycosylation profiles of airway epithelium after repair of mechanical injury in guinea pigs. Histochem J, 2000. 32(4): p. 207-16.

[84] Plotkowski, M.C., et al., Differential adhesion of Pseudomonas aeruginosa to human respiratory epithelial cells in primary culture. J Clin Invest, 1991. 87(6): p. 2018-28.

[85] Dorscheid, D.R., et al., Role of cell surface glycosylation in mediating repair of human airway epithelial cell monolayers. Am J Physiol Lung Cell Mol Physiol, 2001. 281(4): p. L982-92.

[86] Allahverdian, S., B.J. Patchell, and D.R. Dorscheid, Carbohydrates and epithelial repair more than just post-translational modification. Current Drug Targets, 2006. 7(5): p. 597-606.

[87] Allahverdian, S., et al., Sialyl Lewis X modification of the epidermal growth factor receptor regulates receptor function during airway epithelial wound repair. Clin Exp Allergy, 2010. 40(4): p. 607-18.

[88] Donaldson, D.J. and J.M. Mason, Inhibition of epidermal cell migration by concanavalin $A$ in skin wounds of the adult newt. J Exp Zool, 1977. 200(1): p. 55-64.

[89] Patchell, B.J. and D.R. Dorscheid, Repair of the injury to respiratory epithelial cells characteristic of asthma is stimulated by Allomyrina dichotoma agglutinin specific serum glycoproteins. Clinical and experimental allergy : journal of the British Society for Allergy and Clinical Immunology, 2006. 36(5): p. 585-593.

[90] Trinkaus-Randall, V., et al., Carbohydrate moieties of the basal lamina: their role in attachment and spreading of basal corneal epithelial cells. Cell Tissue Res, 1988. 251(2): p. 315-23.

[91] Adam, E.C., et al., Role of carbohydrates in repair of human respiratory epithelium using an in vitro model. Clin Exp Allergy, 2003. 33(10): p. 1398-404.

[92] Sato, S. and R.C. Hughes, Binding specificity of a baby hamster kidney lectin for H type I and II chains, polylactosamine glycans, and appropriately glycosylated forms of laminin and fibronectin. J Biol Chem, 1992. 267(10): p. 6983-90.

[93] Woo, H.J., et al., The major non-integrin laminin binding protein of macrophages is identical to carbohydrate binding protein 35 (Mac-2). J Biol Chem, 1990. 265(13): p. 7097-9.

[94] Warfield, P.R., et al., Adhesion of human breast carcinoma to extracellular matrix proteins is modulated by galectin-3. Invasion Metastasis, 1997. 17(2): p. 101-12.

[95] Matarrese, P., et al., Galectin-3 overexpression protects from apoptosis by improving cell adhesion properties. Int J Cancer, 2000. 85(4): p. 545-54.

[96] Cao, Z., et al., Galectin-7 as a potential mediator of corneal epithelial cell migration. Arch Ophthalmol, 2003. 121(1): p. 82-6.

[97] Cao, Z., et al., Galectins-3 and -7, but not galectin-1, play a role in re-epithelialization of wounds. J Biol Chem, 2002. 277(44): p. 42299-305.

[98] Hughes, R.C., Secretion of the galectin family of mammalian carbohydrate-binding proteins. Biochim Biophys Acta, 1999. 1473(1): p. 172-85.

[99] Kojima, K., et al., Affinity purification and affinity characterization of carbohydrate-binding proteins in bovine kidney. J Chromatogr, 1992. 597(1-2): p. 323-30.

[100] Hajjar, K.A. and C.M. Reynolds, alpha-Fucose-mediated binding and degradation of tissuetype plasminogen activator by HepG2 cells. J Clin Invest, 1994. 93(2): p. 703-10.

[101] Kim, J. and K.A. Hajjar, Annexin II: a plasminogen-plasminogen activator co-receptor. Front Biosci, 2002. 7: p. d341-8. 
[102] Liu, J.W., et al., Annexin II expression is reduced or lost in prostate cancer cells and its reexpression inhibits prostate cancer cell migration. Oncogene, 2003. 22(10): p. 1475-85.

[103] Balch, C. and J.R. Dedman, Annexins II and V inhibit cell migration. Exp Cell Res, 1997. 237(2): p. 259-63.

[104] Matsuda, A., et al., Identification and immunohistochemical localization of annexin II in rat cornea. Curr Eye Res, 1999. 19(4): p. 368-75.

[105] Raynor, C.M., et al., Annexin II enhances cytomegalovirus binding and fusion to phospholipid membranes. Biochemistry, 1999. 38(16): p. 5089-95.

[106] Compton, T., R.R. Nepomuceno, and D.M. Nowlin, Human cytomegalovirus penetrates host cells by pH-independent fusion at the cell surface. Virology, 1992. 191(1): p. 387-95.

[107] Compton, T., D.M. Nowlin, and N.R. Cooper, Initiation of human cytomegalovirus infection requires initial interaction with cell surface heparan sulfate. Virology, 1993. 193(2): p. 834-41.

[108] Malhotra, R., et al., Isolation and characterisation of potential respiratory syncytial virus receptor(s) on epithelial cells. Microbes Infect, 2003. 5(2): p. 123-33.

[109] Kotelkin, A., et al., Respiratory syncytial virus infection sensitizes cells to apoptosis mediated by tumor necrosis factor-related apoptosis-inducing ligand. J Virol, 2003. 77(17): p. 9156-72.

[110] Chakraborti, S., et al., Regulation of matrix metalloproteinases: an overview. Mol Cell Biochem, 2003. 253(1-2): p. 269-85.

[111] Van Lint, P. and C. Libert, Chemokine and cytokine processing by matrix metalloproteinases and its effect on leukocyte migration and inflammation. J Leukoc Biol, 2007. 82(6): p. 1375-81.

[112] Gueders, M.M., et al., Matrix metalloproteinases (MMPs) and tissue inhibitors of MMPs in the respiratory tract: potential implications in asthma and other lung diseases. Eur J Pharmacol, 2006. 533(1-3): p. 133-44.

[113] Greenlee, K.J., Z. Werb, and F. Kheradmand, Matrix metalloproteinases in lung: multiple, multifarious, and multifaceted. Physiol Rev, 2007. 87(1): p. 69-98.

[114] Trifilieff, A., et al., Pharmacological profile of PKF242-484 and PKF241-466, novel dual inhibitors of TNF-alpha converting enzyme and matrix metalloproteinases, in models of airway inflammation. Br J Pharmacol, 2002. 135(7): p. 1655-64.

[115] Lee, K.S., et al., Doxycycline reduces airway inflammation and hyperresponsiveness in a murine model of toluene diisocyanate-induced asthma. J Allergy Clin Immunol, 2004. 113(5): p. 902-9.

[116] Kumagai, K., et al., Inhibition of matrix metalloproteinases prevents allergen-induced airway inflammation in a murine model of asthma. J Immunol, 1999. 162(7): p. 4212-9.

[117] Demedts, I.K., et al., Matrix metalloproteinases in asthma and COPD. Curr Opin Pharmacol, 2005. 5(3): p. 257-63.

[118] Russell, R.E., et al., Alveolar macrophage-mediated elastolysis: roles of matrix metalloproteinases, cysteine, and serine proteases. Am J Physiol Lung Cell Mol Physiol, 2002. 283(4): p. L867-73.

[119] Bracke, K., et al., Matrix metalloproteinase-12 and cathepsin D expression in pulmonary macrophages and dendritic cells of cigarette smoke-exposed mice. Int Arch Allergy Immunol, 2005. 138(2): p. 169-79. 
[120] Miller, T.L., et al., Expression of matrix metalloproteinases 2, 7 and 9, and their tissue inhibitors 1 and 2, in developing rabbit tracheae. Biol Neonate, 2006. 89(4): p. 236-43.

[121] Prikk, K., et al., In vivo collagenase-2 (MMP-8) expression by human bronchial epithelial cells and monocytes/macrophages in bronchiectasis. J Pathol, 2001. 194(2): p. 232-8.

[122] Lopez-Boado, Y.S., C.L. Wilson, and W.C. Parks, Regulation of matrilysin expression in airway epithelial cells by Pseudomonas aeruginosa flagellin. J Biol Chem, 2001. 276(44): p. 41417-23.

[123] Puchelle, E., et al., [Regeneration of injured airway epithelium]. Ann Pharm Fr, 2006. 64(2): p. 107-13.

[124] Parks, W.C., Y.S. Lopez-Boado, and C.L. Wilson, Matrilysin in epithelial repair and defense. Chest, 2001. 120(1 Suppl): p. 36S-41S.

[125] Coraux, C., et al., Differential expression of matrix metalloproteinases and interleukin-8 during regeneration of human airway epithelium in vivo. J Pathol, 2005. 206(2): p. 160-9.

[126] Adiseshaiah, P., et al., A Fra-1-dependent, matrix metalloproteinase driven EGFR activation promotes human lung epithelial cell motility and invasion. J Cell Physiol, 2008. 216(2): p. 40512.

[127] Goswami, S., et al., Divergent functions for airway epithelial matrix metalloproteinase 7 and retinoic acid in experimental asthma. Nat Immunol, 2009. 10(5): p. 496-503.

[128] Nabeshima, K., et al., Emmprin (basigin/CD147): matrix metalloproteinase modulator and multifunctional cell recognition molecule that plays a critical role in cancer progression. Pathol Int, 2006. 56(7): p. 359-67.

[129] Kadomatsu, K. and T. Muramatsu, [Role of basigin, a glycoprotein belonging to the immunoglobulin superfamily, in the nervous system]. Tanpakushitsu Kakusan Koso, 2004. 49(15 Suppl): p. 2417-24.

[130] Vignola, A.M., et al., HLA-DR and ICAM-1 expression on bronchial epithelial cells in asthma and chronic bronchitis. Am Rev Respir Dis, 1993. 148(3): p. 689-94.

[131] Lackie, P.M., et al., Expression of CD44 isoforms is increased in the airway epithelium of asthmatic subjects. Am J Respir Cell Mol Biol, 1997. 16(1): p. 14-22.

[132] Jouneau, S., et al., EMMPRIN (CD147) regulation of MMP-9 in bronchial epithelial cells in COPD. Respirology, 2011. 16(4): p. 705-12.

[133] Caudroy, S., et al., Expression of the extracellular matrix metalloproteinase inducer (EMMPRIN) and the matrix metalloproteinase-2 in bronchopulmonary and breast lesions. J Histochem Cytochem, 1999. 47(12): p. 1575-80.

[134] Caudroy, S., et al., EMMPRIN-mediated MMP regulation in tumor and endothelial cells. Clin Exp Metastasis, 2002. 19(8): p. 697-702.

[135] Huet, E., et al., Role of emmprin/CD147 in tissue remodeling. Connect Tissue Res, 2008. 49(3): p. 175-9.

[136] Betsuyaku, T., et al., Increased basigin in bleomycin-induced lung injury. Am J Respir Cell Mol Biol, 2003. 28(5): p. 600-6.

[137] Guillot, S., et al., Increased extracellular matrix metalloproteinase inducer (EMMPRIN) expression in pulmonary fibrosis. Exp Lung Res, 2006. 32(3-4): p. 81-97.

[138] Odajima, N., et al., Extracellular matrix metalloproteinase inducer in interstitial pneumonias. Hum Pathol, 2006. 37(8): p. 1058-65. 
[139] Gwinn, W.M., et al., Novel approach to inhibit asthma-mediated lung inflammation using anti-CD147 intervention. J Immunol, 2006. 177(7): p. 4870-9.

[140] Leir, S.H., et al., Increased CD44 expression in human bronchial epithelial repair after damage or plating at low cell densities. Am J Physiol Lung Cell Mol Physiol, 2000. 278(6): p. L112937.

[141] Yu, W.H., et al., CD44 anchors the assembly of matrilysin/MMP-7 with heparin-binding epidermal growth factor precursor and ErbB4 and regulates female reproductive organ remodeling. Genes Dev, 2002. 16(3): p. 307-23.

[142] Polosa, R., et al., Expression of c-erbB receptors and ligands in the bronchial epithelium of asthmatic subjects. J Allergy Clin Immunol, 2002. 109(1): p. 75-81.

[143] White, S.R., et al., Role of very late adhesion integrins in mediating repair of human airway epithelial cell monolayers after mechanical injury. Am J Respir Cell Mol Biol, 1999. 20(4): p. 787-96.

[144] Bishayee, S., Role of conformational alteration in the epidermal growth factor receptor (EGFR) function. Biochem Pharmacol, 2000. 60(8): p. 1217-23.

[145] Stroop, C.J., et al., Characterization of the carbohydrate chains of the secreted form of the human epidermal growth factor receptor. Glycobiology, 2000. 10(9): p. 901-17.

[146] Soderquist, A.M., G. Todderud, and G. Carpenter, The role of carbohydrate as a posttranslational modification of the receptor for epidermal growth factor. Adv Exp Med Biol, 1988. 231: p. 569-82.

[147] Wang, X.Q., et al., Epidermal growth factor receptor glycosylation is required for ganglioside GM3 binding and GM3-mediated suppression [correction of suppresion] of activation. Glycobiology, 2001. 11(7): p. 515-22.

[148] Konishi, A. and B.C. Berk, Epidermal growth factor receptor transactivation is regulated by glucose in vascular smooth muscle cells. J Biol Chem, 2003. 278(37): p. 35049-56. Epub 2003 Jun 26.

[149] Partridge, E.A., et al., Regulation of cytokine receptors by Golgi N-glycan processing and endocytosis. Science, 2004. 306(5693): p. 120-4.

[150] Eisenmesser, E.Z., et al., Solution structure of interleukin-13 and insights into receptor engagement. Journal of Molecular Biology, 2001. 310(1): p. 231-241.

[151] Hershey, G.K.K., IL-13 receptors and signaling pathways: An evolving web. Journal of Allergy and Clinical Immunology, 2003. 111(4): p. 677-690.

[152] Minty, A., et al., Interleukin-13 is a new human lymphokine regulating inflammatory and immune responses. Nature, 1993. 362(6417): p. 248-250.

[153] Liang, H., et al., SUMF2 interacts with interleukin-13 and inhibits interleukin-13 secretion in bronchial smooth muscle cells. Journal of cellular biochemistry, 2009. 108(5): p. 10761083.

[154] Vladich, F.D., et al., IL-13 R130Q, a common variant associated with allergy and asthma, enhances effector mechanisms essential for human allergic inflammation. The Journal of clinical investigation, 2005. 115(3): p. 747-754.

[155] McKenzie, A.N., et al., Interleukin 13, a T-cell-derived cytokine that regulates human monocyte and B-cell function. Proceedings of the National Academy of Sciences of the United States of America, 1993. 90(8): p. 3735-3739. 
[156] Schmid-Grendelmeier, P., et al., Eosinophils express functional IL-13 in eosinophilic inflammatory diseases. Journal of immunology (Baltimore, Md.: 1950), 2002. 169(2): p. 1021-1027.

[157] Wills-Karp, M., Interleukin-13 in asthma pathogenesis. Immunological reviews, 2004. 202(Journal Article): p. 175-190.

[158] Allahverdian, S., et al., Secretion of IL-13 by airway epithelial cells enhances epithelial repair via HB-EGF. Am J Respir Cell Mol Biol, 2008. 38(2): p. 153-60.

[159] Zurawski, G. and J.E. de Vries, Interleukin 13 elicits a subset of the activities of its close relative interleukin 4. Stem cells (Dayton, Ohio), 1994. 12(2): p. 169-174.

[160] Zurawski, G. and J.E. de Vries, Interleukin 13, an interleukin 4-like cytokine that acts on monocytes and B cells, but not on T cells. Immunology today, 1994. 15(1): p. 19-26.

[161] Hart, P.H., et al., Potential antiinflammatory effects of interleukin 4: suppression of human monocyte tumor necrosis factor alpha, interleukin 1, and prostaglandin E2. Proceedings of the National Academy of Sciences of the United States of America, 1989. 86(10): p. 38033807.

[162] Pope, S.M., et al., IL-13 induces eosinophil recruitment into the lung by an IL-5- and eotaxindependent mechanism. The Journal of allergy and clinical immunology, 2001. 108(4): p. 594-601.

[163] Luttmann, W., et al., Activation of human eosinophils by IL-13. Induction of CD69 surface antigen, its relationship to messenger RNA expression, and promotion of cellular viability. Journal of immunology (Baltimore, Md.: 1950), 1996. 157(4): p. 1678-1683.

[164] Bochner, B.S., et al., IL-13 selectively induces vascular cell adhesion molecule-1 expression in human endothelial cells. Journal of immunology (Baltimore, Md.: 1950), 1995. 154(2): p. 799-803.

[165] Grunstein, M.M., et al., IL-13-dependent autocrine signaling mediates altered responsiveness of IgE-sensitized airway smooth muscle. American journal of physiology.Lung cellular and molecular physiology, 2002. 282(3): p. L520-8.

[166] Akiho, H., et al., Role of IL-4, IL-13, and STAT6 in inflammation-induced hypercontractility of murine smooth muscle cells. American journal of physiology.Gastrointestinal and liver physiology, 2002. 282(2): p. G226-32.

[167] Booth, B.W., et al., Interleukin-13 induces proliferation of human airway epithelial cells in vitro via a mechanism mediated by transforming growth factor-alpha. American journal of respiratory cell and molecular biology, 2001. 25(6): p. 739-743.

[168] Fichtner-Feigl, S., et al., IL-13 signaling through the IL-13alpha2 receptor is involved in induction of TGF-beta1 production and fibrosis. Nature medicine, 2006. 12(1): p. 99-106.

[169] Li, L., et al., Effects of Th2 cytokines on chemokine expression in the lung: IL-13 potently induces eotaxin expression by airway epithelial cells. Journal of immunology (Baltimore, Md.: 1950), 1999. 162(5): p. 2477-2487.

[170] Laoukili, J., et al., IL-13 alters mucociliary differentiation and ciliary beating of human respiratory epithelial cells. The Journal of clinical investigation, 2001. 108(12): p. 1817-1824.

[171] Zhu, Z., et al., Pulmonary expression of interleukin-13 causes inflammation, mucus hypersecretion, subepithelial fibrosis, physiologic abnormalities, and eotaxin production. The Journal of clinical investigation, 1999. 103(6): p. 779-788. 
[172] Shim, J.J., et al., IL-13 induces mucin production by stimulating epidermal growth factor receptors and by activating neutrophils. American journal of physiology.Lung cellular and molecular physiology, 2001. 280(1): p. L134-40.

[173] Leonard, W.J. and J.X. Lin, Cytokine receptor signaling pathways. The Journal of allergy and clinical immunology, 2000. 105(5): p. 877-888.

[174] Arima, K., et al., Characterization of the interaction between interleukin-13 and interleukin13 receptors. The Journal of biological chemistry, 2005. 280(26): p. 24915-24922.

[175] Guo, J., et al., Chromosome mapping and expression of the human interleukin-13 receptor. Genomics, 1997. 42(1): p. 141-145.

[176] Andrews, A.L., et al., Kinetic analysis of the interleukin-13 receptor complex. The Journal of biological chemistry, 2002. 277(48): p. 46073-46078.

[177] Miloux, B., et al., Cloning of the human IL-13R $\alpha 1$ chain and reconstitution with the IL-4R $\alpha$ of a functional IL-4/IL-13 receptor complex. FEBS letters, 1997. 401(2-3): p. 163-166.

[178] Aman, M.J., et al., cDNA cloning and characterization of the human interleukin 13 receptor alpha chain. The Journal of biological chemistry, 1996. 271(46): p. 29265-29270.

[179] Wang, I.M., et al., STAT-1 is activated by IL-4 and IL-13 in multiple cell types. Molecular immunology, 2004. 41(9): p. 873-884.

[180] Hirst, S.J., et al., Selective induction of eotaxin release by interleukin-13 or interleukin-4 in human airway smooth muscle cells is synergistic with interleukin-1beta and is mediated by the interleukin-4 receptor alpha-chain. American journal of respiratory and critical care medicine, 2002. 165(8): p. 1161-1171.

[181] Yasuo, M., et al., Relationship between calcium-activated chloride channel 1 and MUC5AC in goblet cell hyperplasia induced by interleukin-13 in human bronchial epithelial cells. Respiration; international review of thoracic diseases, 2006. 73(3): p. 347-359.

[182] Wei, L.H., et al., IL-4 and IL-13 upregulate arginase I expression by cAMP and JAK/STAT6 pathways in vascular smooth muscle cells. American journal of physiology.Cell physiology, 2000. 279(1): p. C248-56.

[183] Daines, M.O. and G.K. Hershey, A novel mechanism by which interferon-gamma can regulate interleukin (IL)-13 responses. Evidence for intracellular stores of IL-13 receptor alpha2 and their rapid mobilization by interferon-gamma. The Journal of biological chemistry, 2002. 277(12): p. 10387-10393.

[184] David, M., et al., Induction of the IL-13 receptor alpha2-chain by IL-4 and IL-13 in human keratinocytes: involvement of STAT6, ERK and p38 MAPK pathways. Oncogene, 2001. 20(46): p. 6660-6668.

[185] Caput, D., et al., Cloning and characterization of a specific interleukin (IL)-13 binding protein structurally related to the IL-5 receptor alpha chain. The Journal of biological chemistry, 1996. 271(28): p. 16921-16926.

[186] Lupardus, P.J., M.E. Birnbaum, and K.C. Garcia, Molecular basis for shared cytokine recognition revealed in the structure of an unusually high affinity complex between IL-13 and IL-13Ralpha2. Structure (London, England : 1993). 18(3): p. 332-342.

[187] Kioi, M., S. Seetharam, and R.K. Puri, N-linked glycosylation of IL-13R alpha2 is essential for optimal IL-13 inhibitory activity. FASEB journal : official publication of the Federation of American Societies for Experimental Biology, 2006. 20(13): p. 2378-2380. 
[188] Konstantinidis, A.K., et al., Cellular localization of interleukin 13 receptor alpha2 in human primary bronchial epithelial cells and fibroblasts. Journal of investigational allergology \& clinical immunology : official organ of the International Association of Asthmology (INTERASMA) and Sociedad Latinoamericana de Alergia e Inmunologia, 2008. 18(3): p. 174-180.

[189] Andrews, A.L., et al., IL-13 receptor alpha 2: a regulator of IL-13 and IL-4 signal transduction in primary human fibroblasts. The Journal of allergy and clinical immunology, 2006. 118(4): p. 858-865.

[190] Donaldson, D.D., et al., The Murine IL-13 Receptor \{alpha\}2: Molecular Cloning, Characterization, and Comparison with Murine IL-13 Receptor \{alpha\}1. The Journal of Immunology, 1998. 161(5): p. 2317-2324.

[191] Kawakami, K., et al., The interleukin-13 receptor alpha2 chain: an essential component for binding and internalization but not for interleukin-13-induced signal transduction through the STAT6 pathway. Blood, 2001. 97(9): p. 2673-2679.

[192] Zhang, J.G., et al., Identification, purification, and characterization of a soluble interleukin (IL)-13-binding protein. Evidence that it is distinct from the cloned Il-13 receptor and Il-4 receptor alpha-chains. The Journal of biological chemistry, 1997. 272(14): p. 9474-9480.

[193] Wilson, M.S., et al., IL-13Ralpha2 and IL-10 coordinately suppress airway inflammation, airway-hyperreactivity, and fibrosis in mice. The Journal of clinical investigation, 2007. 117(10): p. 2941-2951.

[194] Smirnov, D.V., et al., Tandem arrangement of human genes for interleukin-4 and interleukin13: resemblance in their organization. Gene, 1995. 155(2): p. 277-281.

[195] Heinzmann, A., et al., Genetic variants of IL-13 signalling and human asthma and atopy. Human molecular genetics, 2000. 9(4): p. 549-559.

[196] Howard, T.D., et al., Gene-gene interaction in asthma: IL4RA and IL13 in a Dutch population with asthma. American Journal of Human Genetics, 2002. 70(1): p. 230-236.

[197] Tarazona-Santos, E. and S.A. Tishkoff, Divergent patterns of linkage disequilibrium and haplotype structure across global populations at the interleukin-13 (IL13) locus. Genes and immunity, 2005. 6(1): p. 53-65.

[198] Madhankumar, A.B., A. Mintz, and W. Debinski, Alanine-scanning mutagenesis of alphahelix D segment of interleukin-13 reveals new functionally important residues of the cytokine. The Journal of biological chemistry, 2002. 277(45): p. 43194-43205.

[199] Semlali, A., et al., Thymic stromal lymphopoietin-induced human asthmatic airway epithelial cell proliferation through an IL-13-dependent pathway. The Journal of allergy and clinical immunology, 2010. 125(4): p. 844-850.

[200] Singhera, G.K., R. MacRedmond, and D.R. Dorscheid, Interleukin-9 and -13 inhibit spontaneous and corticosteroid induced apoptosis of normal airway epithelial cells. Experimental lung research, 2008. 34(9): p. 579-598.

[201] Wadsworth, S., D. Sin, and D. Dorscheid, Clinical update on the use of biomarkers of airway inflammation in the management of asthma. J Asthma Allergy, 2011. 4: p. 77-86.

[202] Watanabe, T., et al., Increased levels of HMGB-1 and endogenous secretory RAGE in induced sputum from asthmatic patients. Respir Med, 2011. 105(4): p. 519-25. 
[203] Reddel, H.K., et al., An official American Thoracic Society/European Respiratory Society statement: asthma control and exacerbations: standardizing endpoints for clinical asthma trials and clinical practice. Am J Respir Crit Care Med, 2009. 180(1): p. 59-99.

[204] D'Amico, A., et al., An investigation on electronic nose diagnosis of lung cancer. Lung Cancer, 2010. 68(2): p. 170-6.

[205] Payne, D.N., et al., Relationship between exhaled nitric oxide and mucosal eosinophilic inflammation in children with difficult asthma, after treatment with oral prednisolone. Am J Respir Crit Care Med, 2001. 164(8 Pt 1): p. 1376-81.

[206] Schleich, F.N., et al., Exhaled nitric oxide thresholds associated with a sputum eosinophil count $>1=3 \%$ in a cohort of unselected patients with asthma. Thorax, 2010. 65(12): p. 1039-44.

[207] Jiang, J., et al., Nitric oxide gas phase release in human small airway epithelial cells. Respir Res, 2009. 10: p. 3.

[208] Kostikas, K., et al., Exhaled NO and exhaled breath condensate $p H$ in the evaluation of asthma control. Respir Med, 2011. 105(4): p. 526-32.

[209] Gessner, C., et al., Angiogenic markers in breath condensate identify non-small cell lung cancer. Lung Cancer, 2010. 68(2): p. 177-84.

[210] Bloemen, K., et al., A new approach to study exhaled proteins as potential biomarkers for asthma. Clin Exp Allergy, 2011. 41(3): p. 346-56.

[211] Lessard, A., et al., Obesity and asthma: a specific phenotype? Chest, 2008. 134(2): p. 317-23.

[212] Sin, D.D., et al., Serum PARC/CCL-18 Concentrations and Health Outcomes in Chronic Obstructive Pulmonary Disease. Am J Respir Crit Care Med, 2011. 183(9): p. 1187-1192.

[213] Wedzicha, J.A., et al., Acute exacerbations of chronic obstructive pulmonary disease are accompanied by elevations of plasma fibrinogen and serum IL-6 levels. Thromb Haemost, 2000. 84(2): p. 210-5.

[214] Chang, C.L., et al., Biochemical markers of cardiac dysfunction predict mortality in acute exacerbations of COPD. Thorax, 2011.

[215] Lowhagen, O., et al., The inflammatory marker serum eosinophil cationic protein (ECP) compared with PEF as a tool to decide inhaled corticosteroid dose in asthmatic patients. Respir Med, 2002. 96(2): p. 95-101.

[216] Dosanjh, A., et al., Elevated Serum Eosinophil Cationic Protein Levels in Cystic Fibrosis, Pediatric Asthma, and Bronchiolitis. Pediatric Asthma, Allergy \& Immunology, 1996. 10(4): p. 169-173.

[217] Trulson, A., et al., The functional heterogeneity of eosinophil cationic protein is determined by a gene polymorphism and post-translational modifications. Clin Exp Allergy, 2007. 37(2): p. 208-18.

[218] Sekiya, T., et al., Increased levels of a TH2-type CC chemokine thymus and activationregulated chemokine (TARC) in serum and induced sputum of asthmatics. Allergy, 2002. 57(2): p. 173-7.

[219] Leung, T.F., et al., Plasma concentration of thymus and activation-regulated chemokine is elevated in childhood asthma. J Allergy Clin Immunol, 2002. 110(3): p. 404-9.

[220] Stephan, V., et al., Determination of N-methylhistamine in urine as an indicator of histamine release in immediate allergic reactions. J Allergy Clin Immunol, 1990. 86(6 Pt 1): p. 862-8. 
[221] Takei, S., et al., Urinary N-methylhistamine in asthmatic children receiving azelastine hydrochloride. Ann Allergy Asthma Immunol, 1997. 78(5): p. 492-6.

[222] Sansuk, K., et al., GPCR proteomics: mass spectrometric and functional analysis of histamine H1 receptor after baculovirus-driven and in vitro cell free expression. J Proteome Res, 2008. 7(2): p. 621-9.

[223] Saude, E.J., et al., Metabolomic profiling of asthma: diagnostic utility of urine nuclear magnetic resonance spectroscopy. J Allergy Clin Immunol, 2011. 127(3): p. 757-64 e1-6. 